This article has been retracted: please see INNOVATIONS in pharmacy retraction policy (https://pubs.lib.umn.edu/index.php/innovations/policies). This article has been retracted by the Editor and Publisher due to the inappropriate use of previously published work. 


\title{
The Excellence of Pharmacy Practice
}

AK Mohiuddin, Assistant Professor

Department of Pharmacy, World University of Bangladesh, Bangladesh

\begin{abstract}
Over the past 50 years, the role of pharmacists has evolved along with the health care needs of our population. In addition to dispensing medications and ensuring patient safety, today's pharmacists are taking a larger role as medical counselors, educators and advocates. They are integral part of the health care team, and are among the most trusted and accessible health care professionals. This accessibility allows them to perform more patient care activities, including counseling, medication management, and preventive care screenings. Beyond the care provided to individual patients, pharmacists have expanded their reach to influence the public health of communities. A pharmacist is uniquely positioned to provide disease state management through appropriate medication therapy management that has been demonstrated to improve patient outcomes and decrease overall health care costs. This role is more important than ever as the environment is demanding new practice and payment models that are required to further optimize care and outcomes while addressing the unsustainable increases in health care costs.
\end{abstract}

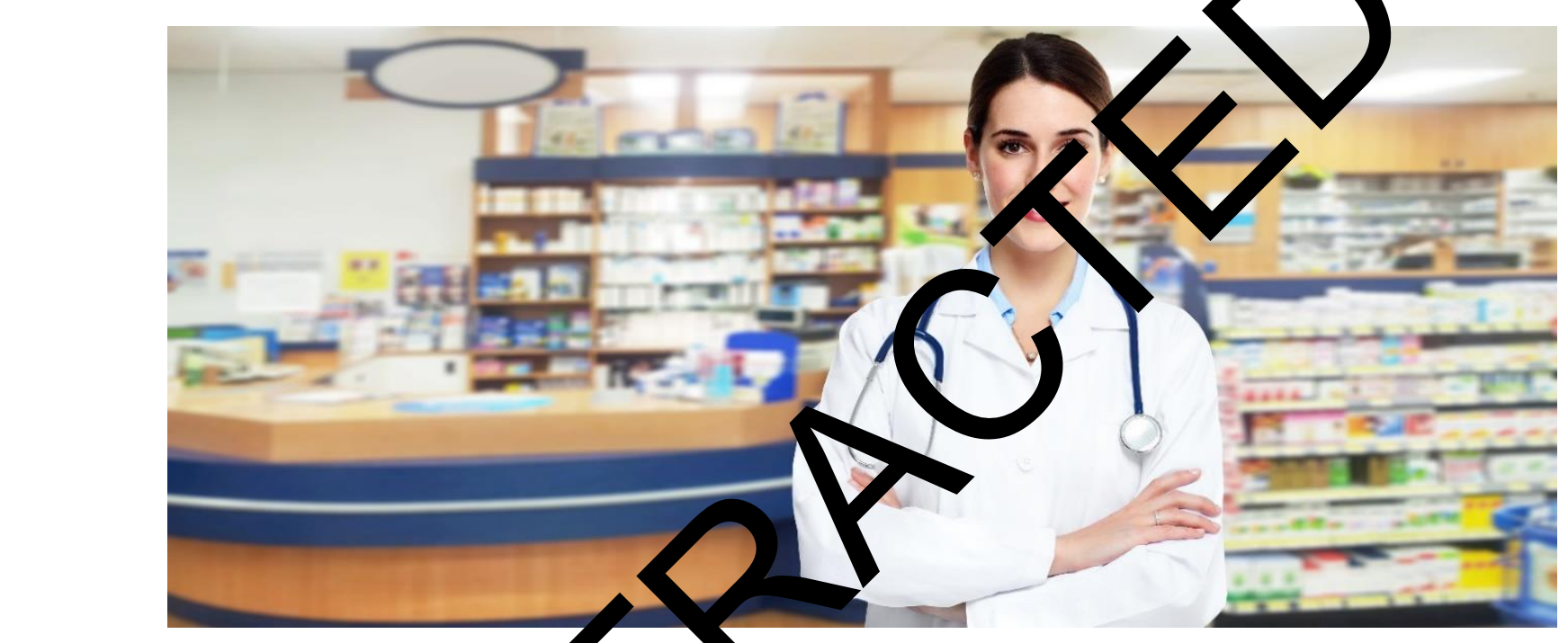

Keywords: HMO; Patient Compliance; Mrdican $n$ Adherence; Pharmacy Profession; Medicine

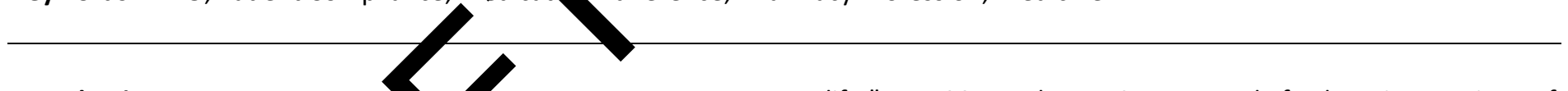

\section{Introduction}

Pharmacy is the art and medications and the $p$ the public. It involves

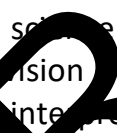
of eparis and dispensing drug ated information to of prescription orders; the compounding, labeli and dispensing of drugs and devices; drug product select 3 and drug utilization reviews; patient monitoring and intervention; and the provision of cognitive services related to use of medications and devices. The current philosophy or approach to professional practice in pharmacy is designated as pharmaceutical care. This concept holds that the important role of the pharmacist is "the responsible provision of drug therapy for the purpose of achieving definite outcomes that improve a patient's quality of

Corresponding author: AK Mohiuddin, Assistant Professor Department of Pharmacy, World University of Bangladesh 151/8, Green Road, Dhanmondi, Dhaka - 1205, Bangladesh Email: trymohi@gmail.com; Phone: +8801716477485 life." In 2015, the RPS proposed further integration of pharmacists into general practices outlining the various benefits that pharmacists could provide. Australia, New Zealand and Canada have shown positive GP responses towards the integration of pharmacists into general practices. GPs recognized that having a practice-based pharmacist decreased their workload and allowed them to focus on their diagnostic and prescribing roles, while pharmacists provided expert medication advice and patient counselling. The profession of Pharmacy is classically practiced in the three main areas of Pharmacy Practice: community, clinical, and hospital. It is now generally accepted that the clinic for a pharmacy practitioner is not confined to the hospital wards. Every place (even a community pharmacy) where medication is used for the prevention, diagnosis, and treatment of any clinical condition, that is considered to be the interface of pharmacist and patient, should be recognized as the pharmacist's clinic. 


\section{APhA Practice for Pharmaceutical Care}

- Preparation of medications by reviewing and interpreting physician orders; detecting therapeutic incompatibilities.

- Dispensing of medications by compounding, packaging, and labeling pharmaceuticals.

- Controlling medications by monitoring drug therapies; advising interventions.

- Completes pharmacy operational requirements by organizing and directing technicians' workflow; verifying their preparation and labeling of pharmaceuticals; verifying order entries, charges, and inspections.

- Providing pharmacological information by answering questions and requests of health care professionals; counseling patients on drug therapies.

- Developing hospital staff's pharmacological knowledge by participating in clinical programs; training pharmacy staff, students, interns, externs, residents, and health care professionals.

- Complying with state and federal drug laws as regulated by the state board of pharmacy, the drug enforcement administration, and the food and drug administration by monitoring nursing unit inspections; maintaining records for controlled substances; removing outdated and damaged drugs from the pharmacy inventory; supervising the work results of support personnel; maintaining current registration; studying existing and new legislation. anticipating legislation; advising management on neede actions.

- Protecting patients and technicians by ad alli to infection-control protocols.

- Maintaining safe and clean working complying with procedures, rules, and

- Maintaining pharmacological knoy $e a_{0}$ by atto ding educational workshops; rryiewing professional publications; establishing pers al networks; pricipating in professional societies.

- Contribution towards team ef oy acco plishing related results as needed [1]

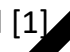

\begin{tabular}{|c|l|}
\hline \multicolumn{2}{|c|}{ Exhibit 1. Scholarly Ad Aation or PHARMACIST [2] } \\
\hline P & Patience \\
\hline H & Honesty \\
\hline A & Alertness \\
\hline R & Research \\
\hline M & Motivator \\
\hline A & Administrator \\
\hline C & Courageous \\
\hline I & Intelligent \\
\hline S & Studious \\
\hline T & Thinker \\
\hline
\end{tabular}

\section{Scope of Pharmacists}

A Pharmacist with the above skills and attitudes should make himself an indispensable partner in health care system of a nation. Pharmacy a complete profession: Pharmacists reflect on every sector of society in the form of:

- Artists - designing a drug dosage form.

- Lawyer - having fair knowledge of laws and legislation about the drug.

- Engineer - having sound technical knowledge.

- Entrepreneur - with sound knowledge of management, accounting, marketing, Counseling.

- Health professional - having fair knowledge regarding health [2].

Learning "Objectives fo the ph macists" roles in health promotion and disease pention a listed below.

- Define, comp and the terms health, health promotion d dise pro stion.

- Explain the cance health promotion and disease preve con efto s.

- Lis an distinguis amples of promotion and prevention activities.

Describe the for pharmacist and pharmacy student involvment in health promotion and disease prevention. Identi opportunities and challenges for pharmacists to prov health promotion and disease prevention services [3].

Academic Pharmacist: In academic pharmacist focus on teaching, research and training of the upcoming pharmacist. Academic institute are major source of pharmacist, who add professional into health care system. By arranging seminar, project, or system academics, pharmacist plays valuable role in health care system. Academicians identify, educate and train student pharmacists to be change agents for the profession so they can influence and create more team-based care opportunities for pharmacy practice. Academic institutions have changed their curricula to meet the future needs of teambased care for the profession [4].

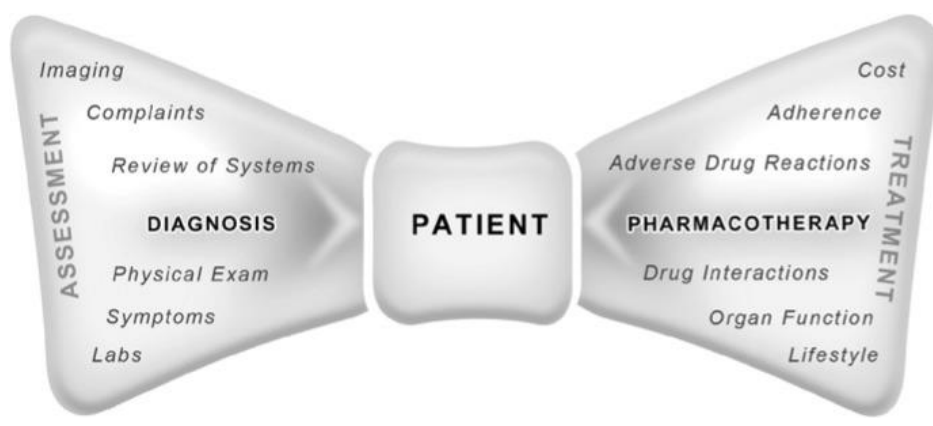

Figure 1. The Bowtie Phenomenon of Team-Based Care. As reform of the US health care system continues, the symbiotic relationship between the physician and pharmacist should be at the center of the patient care model. The Patient Centered 
Primary Care Collaborative described the importance of focusing on a comprehensive approach to pharmacotherapy management in chronic diseases through a team-based approach. A visual representation of this approach can be thought of as a "bowtie phenomenon". This bowtie describes a relationship in which the diagnostician (physician) and pharmacotherapy manager (pharmacist) are able to use their specialized training to collaborate with one another. Keeping these roles and talents in mind, the pharmacy profession needs to train students how to build and be part of effective teams. Literature suggests that pharmacists' perceptions of their professional role does not always include describing themselves as being in patient-centered roles. However, supporting information suggests that pharmacists can contribute to teambased care (Source: Ferreri SP, Cross LB, Hanes SD, Jenkins $T$, Meyer D, Pittenger A. Academic Pharmacy: Where is Our Influence? Am J Pharm Educ. 2017;81(4):63.)

\section{Industrial Pharmacists}

Research and development: Pharmacist contribute to research, and their expertise in formulation development is of particular relevance to the biological availability of active ingredients.

Manufacture and quality assurance: The pharmacist's broad knowledge of the pharmaceutical sciences ensures an integrated approach to quality assurance (including good manufacturing practice) through the validation of the variou stages of production and the testing of products before release Drug Information: The pharmacist has the knowledge and expertise to provide detailed information on me cin to members of the health profession and the pharmacists provide an information company.

Parent Application and Drug Registrati pharma ist is ideally qualified to understand an collate the diverse Information required for potent an duthorization s. $m$ missions. Clinical Trials and Post-m ketin Surveillance: The pharmacist has the knowledge drug health care provision required to acl te companies, health prof sional and governments in relation to clinical trials and surveilla

Sales and Marketing: The harmacist, whose professional ethics demand a concern folthe interest of Patients, can contribute to proper marketing practices related to health care and to the provision of appropriate information to health professionals and the public.

Management: The inclusion of pharmacist in all levels of management promotes an ethical approach within management policies.

Primary Care Pharmacist/Prescribing Advisors: These are people work for NHS organizations that are in charge of a range of local. Health services - such as doctor's surgeries and community pharmacies. Their job is to ensure the best use of medicines and resources across the area. In Some places, practice pharmacist or primary care pharmacist also run medication review Clinics and have lots of patient contact.
Community Pharmacists: Pharmacist work at the frontline of healthcare in cities, towns and villages across nation. They work from their own pharmacies or out of local healthcare center and doctors' surgeries. Some community pharmacist owns their own business and enjoy the challenges of financial management and responsibility for staff, stock and premises that this brings. Other work for large high street pharmacy chain and have the opportunity to move around within an established company structure.

Pharmacist with Special Interest: Pharmacists with special interests are involved with developing their skill and expertise in specialist areas such as cancer or diabetes. Almost half of all pharmacists (42\%) offered additional clinical and educational Services to community rems including blood pressure checks, screening for resterol nd osteoporosis, glucose screening and diabet counse $\mathrm{gg}$, tobacco Cessation programs, immuni cions

Hospital Pharm cist: $\forall$ spital armacists are a vital part of the healthcare $r$ Working in either the PHC or private hospitals eing a spita pharmacist means your part of a team ve focus rimly on patients (WHO website).

me-pharmacis specialize as consultant (or as pharmacists with speci-list interests) in many areas as Hematology (blood), ephrolog (kidneys), Respiratory medicine, Cardiology (heart), D. Wgy rinary), Diabetes, Gastroenterology (stomach and intestine), Infection diseases, pediatrics (children) and care of thoserlderly [5-10].

\section{The Healthcare Pharmacists}

The World health organization (WHO) report on "The role of the Pharmacist in the health care system" states that the competence of the Pharmacist is already proven and control.

A. In health promotion and social responsibilities

B. In the direction and administrative of pharmaceutical services

C. In drug regulation and control

D. In the formulation and quality control of pharmaceutical products

E. In the inspection and assessment of drug manufacturing facilities

F. In the assurance of product quality through the distribution chain

G. In drug procurement agencies and

H. In National and institutional formulary \& therapeutics committees [11].

\section{In Health Promotion and Social Responsibilities}

Health promotion is any combination of interventions (i.e., health education and related organizational, economic, and/or political interventions) designed to facilitate behavioral or environmental changes that will improve or protect public health. Health promotion strategies focus on community-based interventions and partnerships to maintain wellness and to help modify individual behaviors, such as unhealthy lifestyles. In 
other words, health promotion involves community interventions that help a person increase control over and improve his or her own health. Disease prevention is defined as activities that are aimed to prevent and control disease, stop the disease processes, or reduce the consequences of disease. Disease prevention activities focus on individuals and communities with identifiable risk factors that can be targeted for effective intervention. Thus, in contrast to health promotion, disease prevention efforts emanate more from health providers than from individuals. A Pharmacist has an important role to play in health promotion and primary, secondary and tertiary prevention, especially in relation to the management of chronic diseases [12], discussed below in details.
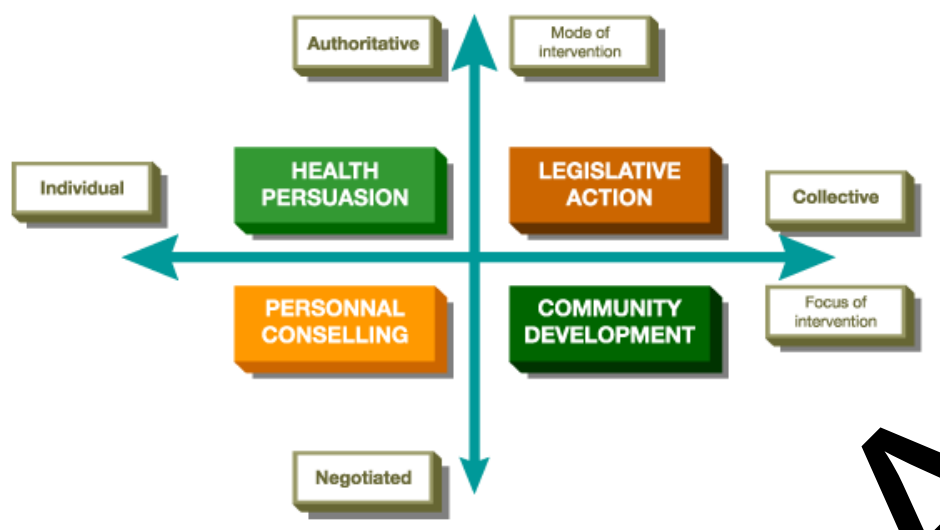

Figure 2. Beattie's Model of Health Promoti $A_{\text {y }}$ /th professionals normally lead health persuasion ac jities. activities are focused at individuals. $T>a_{0}$ ach is authoritative and individuals are not giv any cho es for decisions. An example is a pharmacis coun vlling a VOPD patient to quit smoking for the sakf of his heal Legislative actions are interventions initiated expers or proferssionals to protect the health and welfare of acd munity. An example is the proposed new ording to tally fan smoking in restaurants and most ing' for pu jic arew ersonal counselling focuses on the client's s. cific normally works on one to one basis. The health bh ker acts as a facilitator to discuss and negotiate client needs. $\$$ cisions are made based on the client's wishes. For example, the counselor works with drug abusers to discuss choices between methadone and conventional drug detoxification programs. Community development focuses on interventions targeted at the community level. The community identifies their health needs, seeks to empower and makes the best rational choice (Source: Joanne Perks, Maricris Algoso and Kath Peters, Nurse practitioner (NP) led care: Cervical screening practices and experiences of women attending a women's health center, Collegian, 2018).
Sexually Transmitted Diseases-AIDS: Huge resource of community Pharmacist can educate people in the prevention and information of HIV/AIDS. Although many classes of antiretroviral are available like protease inhibitors, nucleoside reverse transcriptase inhibitors and non-nucleoside reverse transcriptase inhibitors, patients need close monitoring and strict dietary regimen. Pharmacy is a key player in all the NICE publications related to sexual health. They include:

- Contraception quality standard

- Contraceptive services for under 25s

- Long acting reversible contraception

- One to one intervention to prevent STIs and Under 18 conceptions $[13,14]$

Pneumococcal disease and role of a Pharmacist in immunizing adults ainst o pumococcal disease and influenza is discussed. Ph ymonia is leading cause of death due to infection y /dwide chil en aged $<5$ years and is responsible for sproxirytely of the 5.6 million death in this populatinn 1.5 armacists can promote immunization by assuming re role of ed cator, facilitator, and immunizer. Despit ac of specific ention of it in accreditation standards, health-system rsonnel have a duty to vaccinate adults, just as cy do pediac patients. Pharmacists should review mmunization records with patients periodically and at the time f immun ation. As with other drug products, formulary a icion nd the distribution, storage, and handling of vaccines

are important Pharmacist responsibilities.

Cminic disease management: A Pharmacist's role in the control of the chronic disease can range from the support of proven community programs such as screening and disease management clinics for diabetes etc.

Nutrition Counseling: Pharmacists have unique constellation of competencies, including clinical knowledge and skills which place them in an ideal position to contribute to the delivery of nutrition support therapy to patients. Indeed, the professional roles of pharmacists have been evolving from the traditional compounding and dispensing of medications to the modern delivery of direct patient care within multidisciplinary health care teams. Pharmaceutical care (PC) is a practice philosophy, in which the pharmacist responsibly provides medication therapy to patients to achieve definite outcomes that improve their quality of life. There is cumulative evidence to support the positive impact of PC on patient care and health care costs [16]. Oral Health: A Pharmacist has numerous opportunities on a daily basis to positively affect his trend. The American dental association has published pamphlets for dentists and Pharmacists that cover oral structures and diseases prevention to caries, OTC and prescription dental drugs and how these two professions can collaborate.

Environmental Health: About this a Pharmacists should adapt his methods of health educations. A Pharmacist role in environmental health is related primarily to being alert to the conditions prevailing in the community and of working with others to adequately control any of the attendant hazards. 
Epidemiology: Epidemiology is the study of the distribution and determination of health-related events in specific population and the application of this field in the control of these events. Epidemiology relates to the interaction of hosts and their environment with attention to those particular agents in the environment that are causal factors of disease. The alert Pharmacist who can apply the basic principal of Epidemiology in their community will become a significant member of the health team.

Health Measurement: A Pharmacist in the health professional in the most frequent contact with the general public and this function as a community health education makes the Pharmacist role unique. By staying abreast of local health statistics Pharmacist can function as a valuable resource person to researcher's conduction epidemiological studies in the community.

Health Education: Pharmacists are required more than ever to contribute in the area of health promotion (HP), and it is one of the six components that contribute to the health improvement of individuals accessing pharmacy services as stated in the Joint FIP/WHO guideline on good pharmacy practice. The importance of the role of pharmacists in patient counseling is recognized and because of increased accessibility, they are in a key position to provide HP services. Several studies have shown the benefits of pharmacists' involvement in a wide range of important public-health issues including smoking cessation, diabetea hypertension and contraception [17]

Alcohols, Drug Abuse and Smoking Cessation: The diseases of alcoholism and drug abuse also come under the pre community Pharmacist. The Pharmacist has a key ole to lelp individuals who become dependent upon alcghol or seinro sessions can be made by the community armacis o stop smoking.

Vaccinations: Administering vaccines to patie and health care workers is enabling some he ch-system Pha hacists to assume a prominent role in pl c he $\mathrm{h}$. Pharmacists have noticed that immunization needs fe not seing met and, through their advocacy, in eas the ers of patients and employees of health sy ems y have been vaccinated.
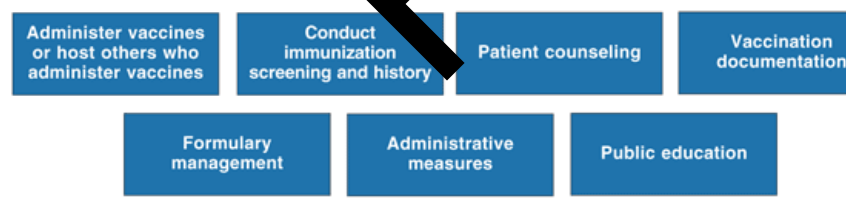

Public education

Figure 3. Categories of Pharmacist Immunization Service.

The NCPA has a free online home-study program, "Creating an Immunization Niche in the Community Pharmacy: A Business Guide," approved by the Accreditation Council for Pharmacy Education for 8 continuing-education contact hours.22 Practitioners must stay informed about current trends in VPD and immunization recommendations.18 Pharmacists who do not administer vaccinations may host other health care professionals to do so, but they still have an obligation to educate and promote full immunization for their patients.18
While immunizations may be provided upon physician order for an individual patient, standing orders or protocols may help increase vaccination levels for some VPDs, such as influenza and pneumococcal disease. This type of practice is promoted by the ACIP (Source: O'Brien KK. Pharmacists' Role in Preventing Vaccine-Preventable Diseases. US Pharm. 2009;34(8):39-45.

Family planning: Drug shops and pharmacies have long been recognized as the first point of contact for health care in developing countries, including family planning (FP) services. Drug shop operators and pharmacists should not be viewed as mere merchants of short-acting contraceptive methods, as this ignores their capacity for in ing uptake of FP services and methods in a systematic d colla rative way with the public sector, social marketin groups o d product distributors. According to the vice de rery g delines of the Ministry of Health and Fam Welf e, Go rment of India, all providers dispensing emee on contraception should be appropriately informed sout ex rgen contraception and should also counse tho clients ol gular contraceptive usage $[18,19]$.

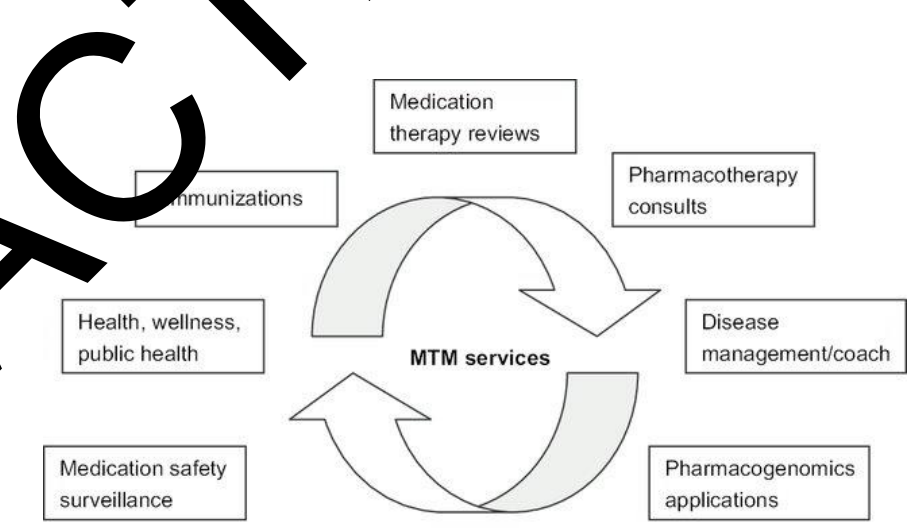

$$
\begin{array}{|l|l|}
\hline \begin{array}{l}
\text { Other clinical } \\
\text { services }
\end{array} & \begin{array}{l}
\text { Anticoagulation } \\
\text { management }
\end{array} \\
\hline
\end{array}
$$

Figure 4. Spectrum of medication therapy management services.

Patients with a potential need for MTM services can be identified by the pharmacist or other healthcare professionals, the health plan, or the patients themselves when medicationrelated problems are suspected. CPP is accordingly evolving within different models including disease management, medication therapy management, patient centered medical home, and accountable care organizations. Pharmacist roles in these models relate to drug therapy management and include therapy introduction, adjustment, or discontinuation, patient counseling and education, and identification, resolution, and prevention of problems leading to drug interactions and adverse reactions. Patients may be especially vulnerable to medicationrelated problems during transitions of care (e.g. hospital admission, hospital to home, hospital to long-term care facility, home to long-term care facility such as when their healthcare setting changes, when they change physicians, or when their 
payer status changes. These transitions of care often result in medication therapy changes that may be due to changes in the patient's needs or resources, the patient's health status or condition, or formulary requirements. It is important that systems be established so that pharmacist-provided MTM services can focus on reconciling the patient's medications and ensuring the provision of appropriate medication management during transitions of care (Source: Management in Pharmacy Practice. Version 2.0 A joint initiative of the American Pharmacists Association and the National Association of Chain Drug Stores Foundation).

Cholesterol Risk Management: Pharmacist care improves the management of outpatients with major modifiable CVD risk factors. Pharmacists can help fill the gap as primary care providers and can contribute to the control of CVD risk factors by their knowledge of medications, their easy accessibility for patients, and their collaborative practice with physicians. More specifically, pharmacists have the opportunity to provide medication instructions to patients at each prescription, to improve safe medication use, and to assist physicians in chronic care [20].

Women Welfare-Pregnancy and Infant Care: Pharmacists, as the most accessible healthcare professionals, can work to empower women in their role as informal caregiver $s$, to communicate to women the necessity to be educated and to support their health literacy. Furthermore, pharmacists ca help women to take control of their reproductive health. They can help women to develop a reproductive reproductive life plan consists of personal goals about having or not having children. pregnancy, pharmacists can provide wo education on contraindicated prenatal vitamins and infant fee ing optis such as breastfeeding and formula feeding A].

Individualization of Drug Thera Tod the latest concept in medicine is towards individualizat of dru herapy. Where judicious patient care joe ned he alization of drug therapy becomes a ne and $a$ harmacist can play a vital role in this. A Pharmacist can ap a separate consultation room and provide counseling to $t$ patient. He can store the details of patient history, allergies and other details necessary for therapy so that the concept of individualization of drug therapy could be implemented.

Radio pharmacy: This is a specialized area of pharmacy, where radioactive materials are produced as drugs for the diagnostics of certain diseases like Thyroid problem by lodine isotope. Here a Pharmacist has a significant role to play.

Consultancy service: It is another area in where a Pharmacist can play a role directly in public health. For independent career $\&$ business consultancy in pharmacy profession is challenging \& demanding $\&$ has a good scope of successful career build up.

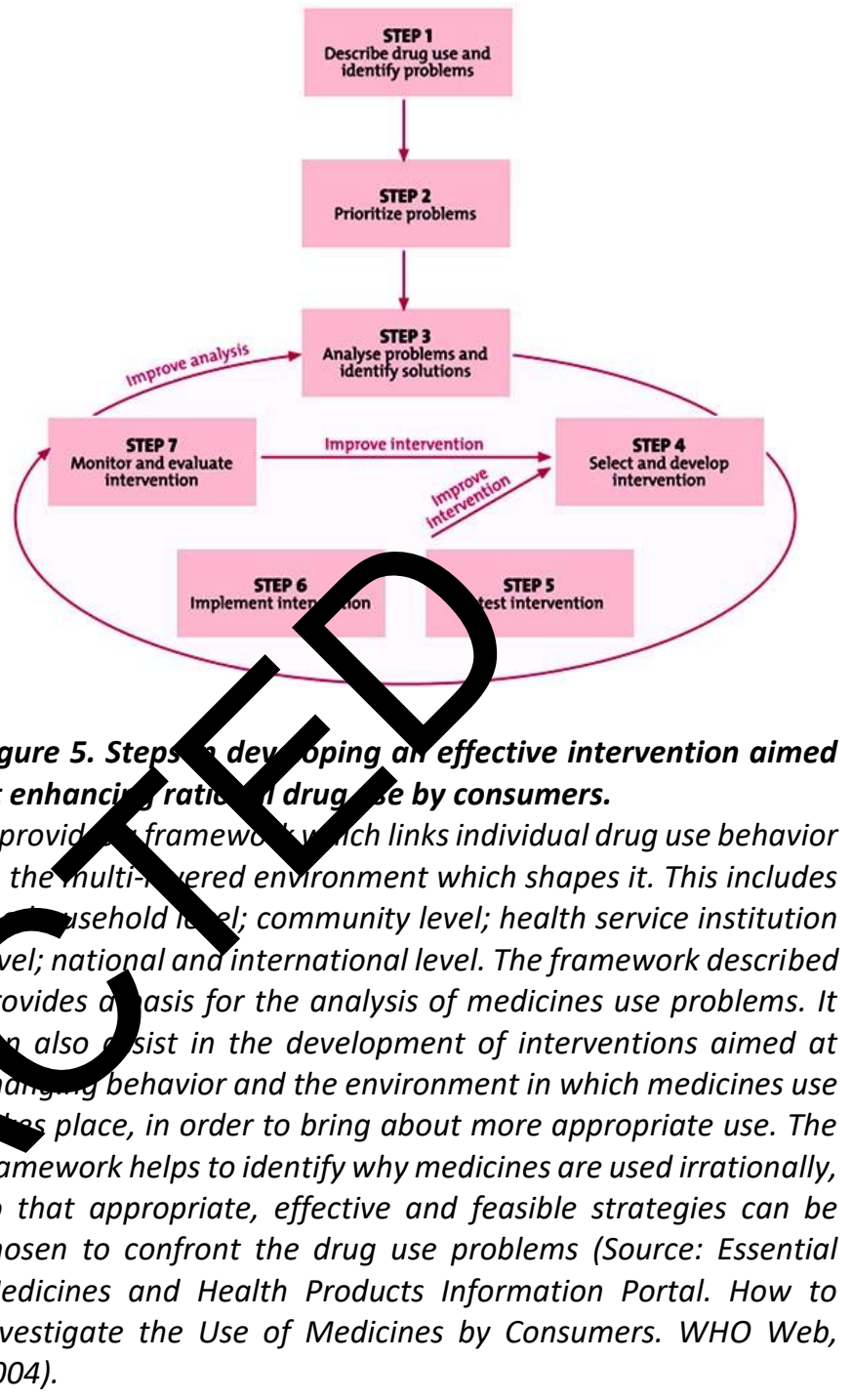

Rational Use of Drugs: The way drugs are procured, stored, distributed, and dispensed and the information given by the pharmacist/dispensers dictates the quality of their use, thus in terms influencing the rational use of medicines. Different models of practice are (1) the drug information practice model, (2) the self-care practice model, (3) the clinical pharmacy practice model, (4) the pharmaceutical care practice model, and (5) the distributive practice model. These models are practiced across the continents alone or in combination based on the understanding of the local pharmaceutical needs, expertise of pharmacist, and their recognition of role [22].

Disease prevention: Distinctions between the types of disease prevention measures are sometimes unclear. Three levels of prevention exist. Here pharmacists play a great role.

a) Primary: Primary prevention is helping people maintain their health or improve the quality of their lives through a healthy lifestyle. An example of primary prevention is the control of infection through immunization.

b) Secondary: Secondary prevention in the early diagnosis and treatment of an already existing disease the use of penicillin in the treatment of a streptococcal infection prevent the onset 
of rheumatic fever. Thus, a pharmacist can perform a vital service by advising patients, who present a febrile illness characterized by a sore throat to see a physician.

c) Tertiary prevention: Tertiary prevention largely consists of rehabilitation. Most chromic disease cannot be cured but their progress can be retarded with maximum benefit to the patient. Much can be done for instance with rheumatoid arthritis to make patients more comfortable and more productive in their daily lives $[23,24]$.

Strategic practice-related efforts that could possibly enable pharmacists to provide health promotion and disease prevention services would include:

- Knowledge of the clinical and demographic characteristics of the community

- Targeted activities based on assessment of diseases associated with the service population in the community

- Development of a written plan for informational and preventive efforts

- Identification of stakeholders and collaborative community partners, such as health departments

- Community and advocacy groups, homeless shelters, institutions, and payers

- Marketing, documenting, and billing of professional services associated with health promotion and disease prevention in order to provide sustainable pharmacybased interventions; and

- Utilization of educational materials, e.g., handout brochures [25].

In the Direction \& Administrative of Pharmaceut al Ser ces: In this branch, there are opportunities to a Phan ci corarn education levels. The largest numbers Pharma ts are involved in marketing \& administration me are man ting people (Pharmacists) educate phricians o community Pharmacists, hospital pharmacist etc. about mo.ufactures product. This can be a rewardin caree or a Pharmacist with right personality \& motivation

\section{In Compounding and $D$ bensip pharmucists}

- Accept and check pro stion aevails

- Script validity

- Safety and appropriatenes.

- Review patient's dispensing history

- Patient-specific factors

- Select product

- Dispensing check

- Label and assemble dispensed products

- Supply prescription to patient/carer: re-check

- Counsel patient/carer on safe and appropriate use
Table 1. Differences between Dispensing and Providing Pharmaceutical Care [26]

\begin{tabular}{|c|c|}
\hline Dispensing & Pharmaceutical Care \\
\hline $\begin{array}{l}\text { Objective is to bring product } \\
\text { to the customer }\end{array}$ & Service business \\
\hline $\begin{array}{l}\text { Decisions focus on the } \\
\text { business. }\end{array}$ & $\begin{array}{l}\text { Objective is to bring the } \\
\text { pharmacist to the patient. }\end{array}$ \\
\hline Inventory generates revenue. & Decisions focus on the patient. \\
\hline $\begin{array}{l}\text { Available service supports the } \\
\text { product. }\end{array}$ & $\begin{array}{l}\text { Patient care generates } \\
\text { revenue. }\end{array}$ \\
\hline $\begin{array}{l}\text { Schedule for repeat } \\
\text { prescription determined by } \\
\text { customer supply of drug } \\
\text { product. }\end{array}$ & $\begin{array}{l}\text { Available product supports the } \\
\text { service. }\end{array}$ \\
\hline $\begin{array}{l}\text { Business is passively } \\
\text { through the generati } \\
\text { prescriptions. }\end{array}$ & $\begin{array}{l}\text { edule for follow-up } \\
\text { de ermined by risk and benefit } \\
\text { drug therapies and needs of }\end{array}$ \\
\hline & $\begin{array}{l}\text { Business is actively sought } \\
\text { through the recruitment of } \\
\text { patients. }\end{array}$ \\
\hline
\end{tabular}

Hospital Manayement: A Pharmacist has a great role to play n hospita administration. The responsibilities of a hospital harmacis are to develop a high quality comprehensive phio cutical service, properly coordinate \& meet the needs the numerous diagnostics \& therapeutic departments, the nursing service, the medical staff, medical equipment of hospital \& the hospital as a whole in the interest of community improving patient care. Clinical pharmacists 'role in patient safety stated below:

- Hospital pharmacists should take responsibility for the management and disposal of waste related to the medicine use process, and advise on disposal of human waste from patients receiving medicines.

- Hospital pharmacists should take responsibility for all aspects of selection, implementation and maintenance of technologies that support the medicine use process, including distribution devices, administration devices, and other equipment.

- Hospital pharmacists should ensure appropriate assessment, development, implementation and maintenance of clinical decision support systems and informatics that guide therapeutic decision-making and improve the medicine use process.

- Hospital pharmacists should support the development of policies regarding the use or medicines brought into the hospital by patients, including the evaluation of appropriateness of complementary and alternative medicines.

- Doses of chemotherapy and other institutionally identified high-risk medicines should be independently checked against the original prescription by at least two health care professionals, one of whom should be a pharmacist, prior to administration. 
- Hospital pharmacists should ensure the development of quality assurance strategies for medicines administration to detect errors and identify priorities for improvement

- An easily accessible reporting system for adverse drug reactions should be established and maintained.

- An easily accessible reporting system for medication errors, including near misses, should be established and maintained.

- Medicines use practices should be self-assessed and compared with benchmarks and best practices to improve safety, clinical effectiveness, and cost-effectiveness.

- Systematic approaches (trigger tools) should be used to provide quantitative data on adverse drug events and optimal medicines use. These data should be regularly reviewed to improve the quality and safety of medicines practices [27-30].

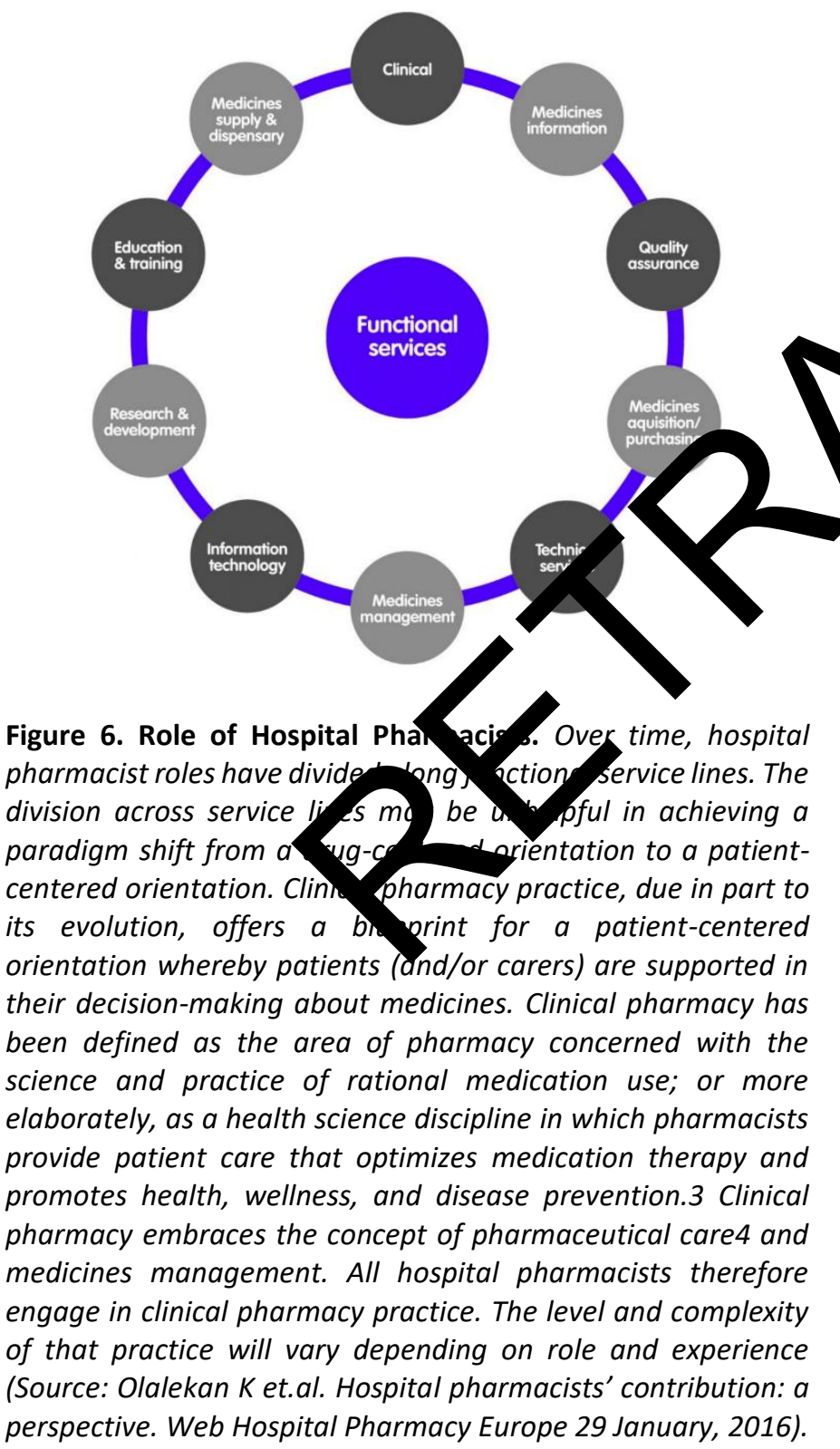

In Health Maintenance Organizations (HMOs): HMOs are open or private associations that give and oversees extensive wellbeing administrations to people enlisted. Here a Pharmacist can play a role in the administration of this kind of organization or give direction. Community pharmacies are very frequently the first contact with the health care system, often before a General Practitioner. There is a high frequency of contacts with low barriers to access to health care: no appointments, no long waiting time, convenient opening hours, and they are located within the community. Regular contacts offer access to a wide range of people, namely, healthy persons, those showing symptoms, patients undergoing treatment, relatives and other care givers; people from all social strata. It would be necessary to purs policies to enhance the utilization of the up apped tentials of community pharmacists, especially primary ealth care is the central focus of health car celiver,

- Perform pa ant as ssme subjective and objective data including ph, ic assessment)

- Have escript autb ity (initiate, adjust, or discontinue tre (tin t) to ma disease through medication use and deliver Vlaborative drug therapy or medication managemen

Orderinterpret and monitor laboratory tests

Formy te clinical assessments and develop therapeutic olan

- Provide care coordination and other health services for wellness and prevention of disease

- Develop partnerships with patients for ongoing (follow-up) care [31-33]

\section{Extended Role of Community Pharmacists}

Community pharmacists have the potential to not only contribute to improving patients' outcomes through safe and effective use of drugs, but also to reduce the cost of healthcare by resolving drug related problems and promoting public health issues. At the same time, the nature of pharmacy practice and community pharmacy is also changing. Along with others, they community pharmacists have following responsibilities:

- Delivery services to household patients

- Services for groups with special needs

- Services for residential homes

- Out of hours services

- Domiciliary visits

- Distribution of welfare food

- Disposal of unwanted medicines

- Sale of prepayment certificates

- Hospital discharge and admission procedures

- Needle and syringe exchange schemes

- Health promotion activities

- Health screening

- Patient referrals to general practitioners and other health professionals

- Development of local formularies

- Provision of professional advice 
- Advice on palliative care

- Supply of disability aids

- Reporting adverse drug reactions

- Provision of quiet area for confidential

- Conversations

- Supply of complementary medicines [34,35]

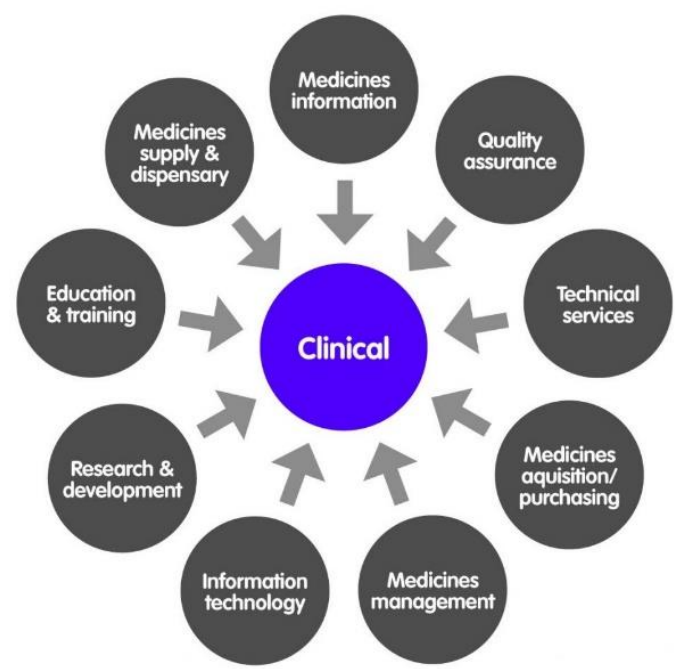

Figure 7. Clinical pharmacy model. The developments of supplementary and independent prescribing roles are enable for a multidisciplinary approach to safe and effective use 0 medicines. Researchers have shown the benefits of this approach: (1) A study looking at a collaborative ar foa to pharmaceutical care from admission to discharg repor $\ \mathrm{~d}$ a reduced prevalence per patient of error at $\mathrm{gdh}$ n aha discharge from adult inpatient care; (2) On ard par ipation of a hospital pharmacist in an intensive are tting haveen shown to reduce prescribing errors $a$ d related tient harm; and (3) Pharmacists attending co ditant-led wara rounds, in addition to undertaking wa ph macist visits make significantly more interventionspen lent th those made by pharmacists undertaking wa pha st visit alone. The increasing use of techn $\mathrm{kgy}$, li Clectronic prescribing systems in hospitals, has affected w w the cunical role is discharged. Access to drug charts and ch ral results outside of the clinical areas (or wards) has resulted in some clinical roles being discharged off-ward. A number of methods have been described for capturing intervention data made by clinical pharmacists onwards (Source: Olalekan $K$ et.al. Hospital pharmacists' contribution: a perspective. Web Hospital Pharmacy Europe 29 January, 2016).

\section{Pharmacists in ICU}

Because of the complexity of drug therapy and the critical nature of patients in ICUs, the attendance of a clinical pharmacist in this setting is an important issue. Studies have reported that the interventions of clinical pharmacists have resulted in a rational drug therapy and improved patient care and treatment costs [36].
Long-term Care: Residents in long-term care are often elderly people with several comorbid conditions, who may be very susceptible to inappropriate prescribing. Although complex medication regimens are often required for these individuals, pharmacists can play a vital role in improving the overall quality of drug therapy. The pharmacist's medication review saves doctors' time; this is particularly the case for patients who are not reviewed opportunistically. Overall, the evidence for the benefit of pharmacists in long-term care settings is quite mixed. Pharmacists can improve clinical outcomes by reducing potentially inappropriate prescribing and MRPs; however, the majority of successful interventions in the literature were multidisciplinary in nature. Economic evaluations of pharmacist interventions in this setting mited, but most studies have shown no significant dif ance h pumanistic and economic outcomes [37].

Ambulatory Care $C$ ics: An ulato care pharmacy practice is defined as the ovisig of in , rated, accessible healthcare services by nha as is who are accountable for addressing medicatio needs, Jevel ring sustained partnerships with patient a practicin the context of family and community. Pharmacist se ices have varying effects on patient outcomes mpored with sual care. CPPs deployed at the medical enter's ambulatory care clinics have had a positive impact on linical an cost outcomes, improving patient care through in vent $n$ s, contributing to readmission reduction efforts, renerating indirect revenue through cost avoidance, and gemerating new revenue through billing for patient visits [3840].

Exhibit 2. Establishing a New Ambulatory Care Practice Site as a Pharmacy Practice Faculty: Key Considerations [101]

- Have a clear vision of the pharmacist services at the practice site

- Be prepared prior to discussions with the medical director, other healthcare providers, and clinic manager, and anticipate questions that may arise

- Ensure that the key stakeholders have a clear understanding of the services that the pharmacist will provide to the patients at the clinic, and inquire regarding the support and resources that the pharmacist can expect from the site

- Prior to committing to a practice site, gather information regarding the feasibility of a successful clinic and seek mutually beneficial goals that will provide benefit and value to pharmacy students and residents, providers, patients, and to the pharmacy practice faculty

- Regular communication with the providers and staff will help identify barriers and help set up a thriving clinical practice site

- Recognize that establishing a new practice is a difficult process, and it may take a considerable amount of time for the pharmacist to become fully integrated into the clinic

- Determine needs versus wants and be prepared to negotiate to establish a successful learning environment

- Be flexible, but if a site is unable to accommodate basic needs to set up a successful practice, consider moving on to identify other sites 
Drug Information Services: Health care providers do not actually use these guidelines. Approximately $10 \%$ to $40 \%$ of patients do not receive care based on updated scientific evidence and more than $20 \%$ of interventions performed are not required or are potentially harmful to patients. Drug information service is a dedicated and specialized service provided by pharmacists to enhance knowledge of medicines use, promote rational prescribing among prescribers, and reduce medication errors. One of the most important aspects of drug information is to be unbiased in its contents. Thus, the unbiased nature of information is of paramount importance to enhance patient outcomes and reduce ADRs [41, 42].

In Drug Regulation \& Control: A Pharmacist in government drug regulatory affair department plays his role by regulating the quality of medications, price of the medications, applying the ethics \& law about medications \& industries.

In the Formulation \& Quality Control of Pharmaceutical Products: The formulation of any medication is only depended on Pharmacist. It is one of the important roles of a Pharmacist. The physical, chemical \& biological quality of a pharmaceutical product intended for administration to patients in the home must be of the highest quality attainable. This quality must be built in to the product in each step of the aseptic compounding process, that is, in the starting components, the design \& operation of the compounding facilities, the control of the environment $\&$ the qualifications of operators all contribute to the final quality of the product, either in a positive or negativ manner. Therefore, the control of quality is a continuous process throughout the compounding of the product ass of the finished product can only confirm the quality alt in the product during its preparation. Here only a Phama t mpray his role.

In the Inspection \& Assessment of th Manufac ring Facilities: Another important duty of Pharma (by joining the government testing laborato \& medicine egulatory service) is inspect the pha aceut industries, their environment, quality of medicatio, acilitig $\&$ assesses the medications.

In the Assurance of $P R$ luct $Q$ ality thrugh the Distribution Chain: Distribution of me con is two types-

a. From industry to marke After produced, before sending to the market ensuring quality of pharmaceutical products is must, because it is directly related with life. Here only a Pharmacist plays a significant role.

b. From hospital to the patient (through prescription): The medication distribution system in hospitals is very complex $\&$ involves in several health care professionals. The usual flow is physician prescribes, Pharmacist dispenses \& nurses administer medication. Here the Pharmacist, who dispenses, has the right to change the medicine which is prescribed by the physician to ensure the quality of that medicine.
In Drug Procurement Agencies: The work of drug procurement agencies is to supply the medication \& find out the possible customer in home $\&$ abroad. Here a Pharmacist plays a great role.

In National and Intuitional Formulary and Therapeutics Committees: During recent years, with the development of the clinical pharmacy movement, a number of clinical Pharmacists on the staff of some departments have developed expertise in specific therapeutic specially areas. Therefore, it was a logical development under the pharmacy \& therapeutics committee. The formulary system has attempted to outline the scientific data on a medication, including its toxicities, untoward side effects, safety profile \& beneficial effects- has been a controversial method of a medication therapy. All these are provided by af mulary mmittee of a nation $\&$ this formulary committee is nstructe by the Pharmacists [43, 44].

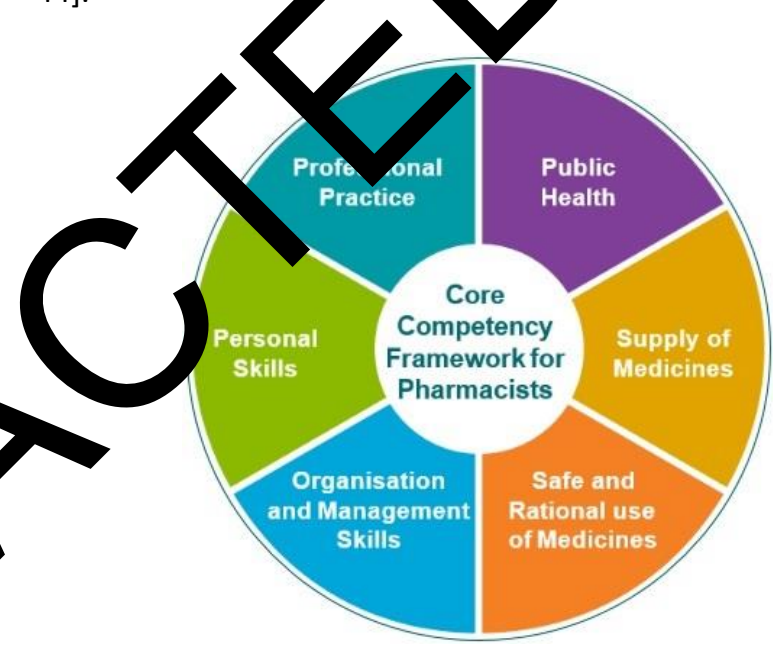

Figure 8. Core Competency Framework. Competencies refer to the knowledge, skills, attitudes and behaviors that an individual develops through education, training and work experience. When combined, these competencies form a competency framework. This framework provides a blueprint for describing the competencies and behaviors of pharmacists in their daily practice. It is intended that the framework would also be used to provide structure and guidance for CPD over the changing demands of a pharmacist's career. The framework is divided into six domains of practice and identifies a number of competencies expected of a pharmacist in each domain. A number of behavioral statements are given for each competency to demonstrate how individuals who have that competency will be behaving in practice. It is used for a number of purposes, including: Assisting pharmacists to reflect on their practice and identify learning needs for CPD; Development of programs by academic institutions; informing the educational standards for accreditation by the PSI of pharmacy degree programs. Providing a platform for the development of specialization and advanced practice within pharmacy. Providing a public statement of the professional role of a pharmacist (Source: Web Pharmaceutical Society of Ireland (PSI). Core Competency Framework) 


\section{Pharmacist's Role Plays in Public Health}

Pharmacist contributions to public health that are not widely reported. This may be partially due to some of these services not being framed within public health categories, so the population impact of their services goes unnoticed. Nearly $93 \%$ of U.S. residents live within five miles of a pharmacy, making the community pharmacy one of the most accessible healthcare institutions. The pharmacist is in a unique position to make essential public health contributions. However, there is limited evidence that patient perspectives on the role of pharmacists has changed. The role of the pharmacist as part of the interdisciplinary team is even more critical in rural locations as many of them are healthcare worker shortage areas, and the pharmacist may be one of the few healthcare professionals in the community [45]. NHS England (NHSE) is facing a growing GP workforce crisis, with continuing problems around GP recruitment, retention, and retirement rates. Approximately $30 \%$ of GP partners have reported not being able to fill a GP vacancy in their practice for at least 12 months (2017-18 survey). Recent studies support clinical pharmacists in General Practice, including their perceived competencies, scope of practice, practice environments, levels of integration, and support needs [46].

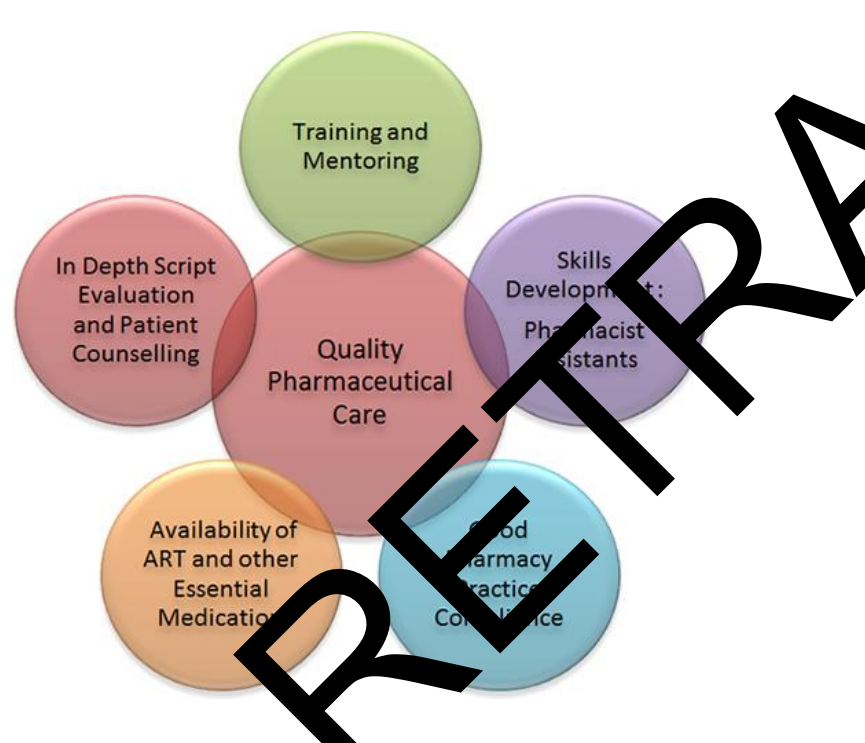

Figure 9. Factors of Quality ve. Prescription for Excellence made a clear commitment to ensuring people had access to pharmaceutical care, which was delivered by pharmacist independent prescribers across all care settings. Significant progress has already been made to build a complementary mix of skills within the pharmacy team, including independent prescribing, communication skills, history taking and advanced clinical assessment skills. A further drive to recruit more pharmacists to undertake these programmers, along with an increase in training places and additional financial resources, will be needed to support the planned capacity increase in pharmacists with advanced clinical skills to meet the needs of the service (Source: NHS Scotland. Achieving Excellence in Pharmaceutical Care a Strategy for Scotland. The Scottish Government, August 2017).

\section{Building Relationships}

Partnerships within pharmacy and public health arenas may provide a platform for evidence-based decision making through processes that focus on common problems and build a foundation for decisions.

Collaboration: IPC is an integral part of the practice of Medicine and Family Medicine. The WHO defines IPC as "multiple health workers from different professional backgrounds work together with patients, families, carers and communities to deliver the highest quality of care". To provide effective, patient-centered care, family physicians must collaborate with other health and social care providers. There are many benefits of collaboration such as ancin the use of scarce resources as many organizations ve limited capital, reduction in the duplication of cost $\lambda d$ ef by de reasing fragmentation of health services improying aty by integrating health outcomes for pat its, improving communication by considerip divers ersp cives on public health issues and increas of ast and derstanding among individuals and organizations 7-49].

Tergency Prep. $\mathrm{c}_{\mathrm{L}}$ edness and Response: During the events of hatural disters, industrial accidents or bioterrorist attacks, ealthcare acilities are often over- whelmed by the influx of panta his can lead to inaccuracy or errors in prescribing the xoper therapy for a patient because of limited staff with little time to treat. This is when pharmacists play a critical role in individualizing medication therapy regimens to select treatment, increase medication effectiveness, and minimize adverse drug events. Pharmacy leaders should (1) review government and community disaster responses and understand the movement of drug supply for each response, (2) create a pharmacy disaster plan, (3) list the essential medications and determine their inventory levels, and (4) establish a staff training program to enhance understanding and implementation of the EOP. If successfully developed and executed, a hospital pharmacy department's EOP has a high rating of success in meeting patient-centered needs in the unforeseen event of a disaster [50].

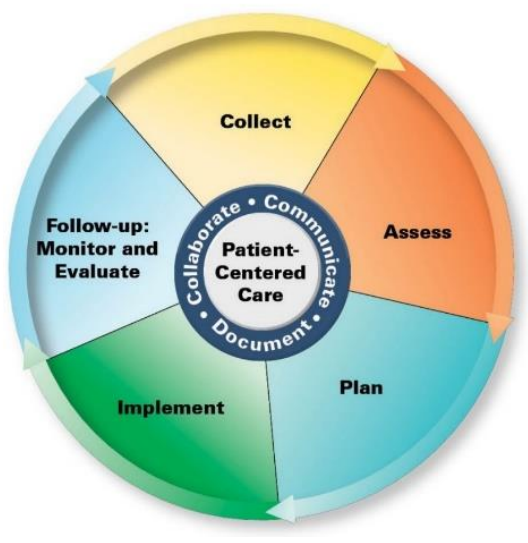


Figure 10. The Pharmacists' Patient Care Process. Collect: The pharmacist assures the collection of necessary subjective and objective information about the patient in order to understand the relevant medical/medication history and clinical status of the patient. Information may be gathered and verified from multiple sources, including existing patient records, the patient, and other health care professionals. Assess: The pharmacist assesses the information collected and analyzes the clinical effects of the patient's therapy in the context of the patient's overall health goals in order to identify and prioritize problems and achieve optimal care. Plan: The pharmacist develops an individualized patient-centered care plan in collaboration with other health care professionals and the patient or caregiver that is evidence-based and cost effective. Implement: The pharmacist implements the care plan in collaboration with other health care professionals and the patient or caregiver [Source: Web Joint Commission of Pharmacy Practitioners $(J C P P)]$

Patient Advocacy: Both hospital and community pharmacists have a significant role to play in advocacy of pharmacy as a profession. Governments and pharmacy governing bodies are continuing to work to increase the scope of practice of pharmacists, leaving us with an incredible opportunity to grow. Pharmacists also need to be taking responsibility for advocating through the interactions we have with patients, other heal care professionals and the public. In order for pharmacists $t$ meet the needs of the medically indigent, further e needed to show that the patient's opinion is va methods can be used to advocate for participation in community collaboratio consumers' rights groups, advocacy organizations which bring communiti educating the public and supportin, policy chans in public health [51].

Patient Centered Approach (Impro Healt Dutcomes): The mission of pharmacists is t nel, peop ac eve optimal health outcomes. Similarly, th missig of publrc health specialists is to promote physical and atal hearth and prevent disease, injury, and disability. Then is overlap in the two mission statements with respect to achirving optimal health outcomes. The JCPP created a profession-wide patient-centered care model known as the PPCP in 2014. The PPCP recommends that pharmacists use a patient-centered approach, in collaboration with other health care providers to optimize patient care. To accomplish this, pharmacists should use evidence-based medicine to collect necessary subjective and objective information, assess the collected information, develop an individualized patient-centered plan, implement the plan, monitor and evaluate the effectiveness of the plan - modifying as needed [52].

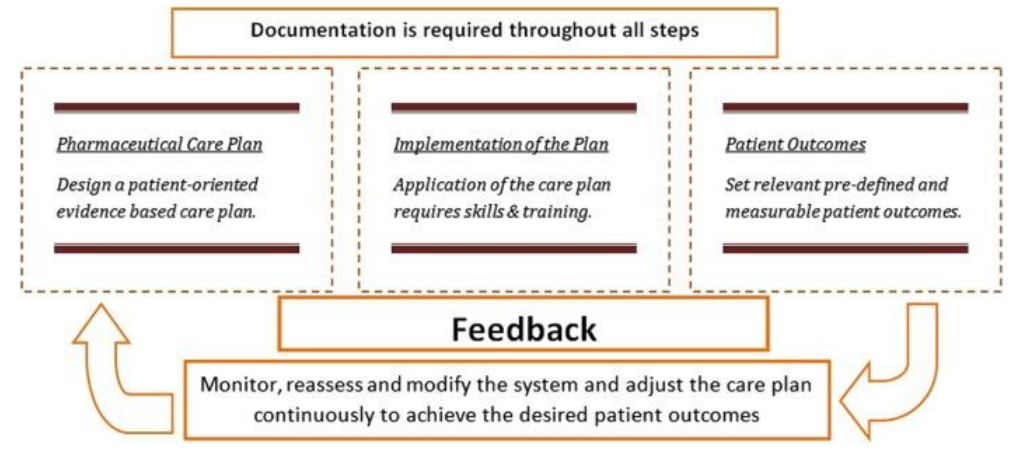

Figure 11. Evidence-based pharmaceutical care. As care providers, pharmacists are effective in providing high quality patient care and being inbe in multidisciplinary clinical teams is needed to giv hem the portunity. Evidence based pharmaceutical carf a no. ral and ogical emerging concept in the modern phar acy practic o chieve high quality and more effective pharm sut are put still more efforts and resources are neede $l o$ pron te ne attitude toward more professional career. $m$ is strom showing that pharmaceutical care lead to imp rement in health outcomes and cost-effective taryy. More es, rts, policies and qualified staff are needed to stablish the "evidence-based pharmaceutical care" as new daily rofession practice. Evidence to support pharmacists in their role as care providers is available to improve the officacy and quality of pharmaceutical care. Education and specialized training practicing evidence-based approach are vital to prepare pharmacists to provide high quality pharmaceutical care (Source: Al-Quteimat OM, Amer AM. Evidence-based pharmaceutical care: The next chapter in pharmacy practice. Saudi Pharmaceutical Journal Volume 24, Issue 4, July 2016, Pages 447-451. https://doi.org/10.1016/j.jsps.2014.07.010)

Minimizing Adverse Drug Events: It has been suggested that closer collaboration between doctors and pharmacists in primary care prevent ADR. Nowadays, pharmacists also ensure the rational and cost-effective use of medicines, promote healthy living, and improve clinical outcomes by actively engaging in direct patient care and collaborating with many healthcare disciplines. With this expanding scope of practice, pharmacists are being recognized as key components in providing individualized patient care as part of interprofessional healthcare teams [37].

Education and Research: The ACPE and Center for the Advancement of Pharmacy Education have encouraged collaboration between healthcare professions and pharmacy by building the skills and confidence of students to optimize patient care and services. They also encourage that pharmacy programs "strive to meet community needs" and evaluate faculty members for their service contributions to the community. Given that emphasis on service, teaching, and research are hallmark evaluation metrics of all institutional programs, conformance is necessary to develop pedagogical 
models that are adoptable. In the public health arena, these goals of pharmacy practice benefit society by creating desirable patient outcomes, minimizing overuse, underuse and misuse of medications, and achieving medication related public health goals [53].

Pharmacist on the Home Care Team: Medication-related problems are common among home care clients who take many medications and have complex medical histories and health problems. Helping clients manage medications can be a challenge for all home care clinicians. By partnering with a college of pharmacy at a large university in the community, the agency successfully included a pharmacist as a member of their home care team. Medication-related problems are often classified four types: Indication, Effectiveness, Safety and compliance $[54,55]$.

Except these, a Pharmacist has important role to play as Chain Drug Store Pharmacist, Grocery Chain Pharmacist, Hospice Pharmacist, Hospital Staff Pharmacist, Managed Care Pharmacist, Military Pharmacist, Nuclear Pharmacist, Oncology Pharmacist, Operating Room Pharmacist, Pediatric Pharmacist, Pharmacist in Non-traditional Settings, Pharmacy Benefits Manager, Poison Control Pharmacist, Primary Care Pharmacist, Psychiatric Pharmacist, Veterinary Pharmacist [56].

\section{Future Roles}

Revolutionary progress in basic biomedical science $\mathrm{ncl}$ ing human genomics, stem-cell biology, immunolog biom lin engineering, and bioinformatics, has pro an unprecedented supply of information fo proving uman health. The rapidly emerging fields of populat genetics and pharmacogenomics highlight the snificance o molecular techniques in the clinical dia ostic aboratory and the potential for application in patien li cted pryacotherapy. Medication-prescribing de oro why ore ongly rely on the results of genotyping of dru metabuaing enzymes. New technology and practice vil allowm dith system pharmacists to reduce treatment fali ss and prevent adverse drug reactions through the proper plication of pharmacogenetic principles. Advances in informatics will permit aggregation and application of population- and patient-specific clinical data in ways that will encourage development of population-specific, evidence-based disease management programs. As medication-use experts, health system pharmacists will need to apply these new tools not simply to improve patient-specific pharmacotherapy but to advance public health. Similarly, innovations in medication delivery technology will allow more complex therapies to be administered outside institutional settings. Patients, caregivers, and health professionals will require education about the safe use of such technologies, as will the legislators and other officials responsible for regulating their use [57-63].

\section{Pharmacy Professional Organizations}

Pharmacy organizations and associations offer many benefits to, and can fulfill many needs for, both pharmacists and technicians. These groups can offer networking, continuing education opportunities, free publications, and leadership opportunities. Although some pharmacy organizations are specific to just pharmacists, there are many organizations available for both pharmacists and pharmacy technicians to join, some of which provide specialty information for specific pharmacy fields. The Table $\mathbf{2}$ lists some pharmacy organizations and their specialties.

Table 2. Pharmacist Organizations [6]

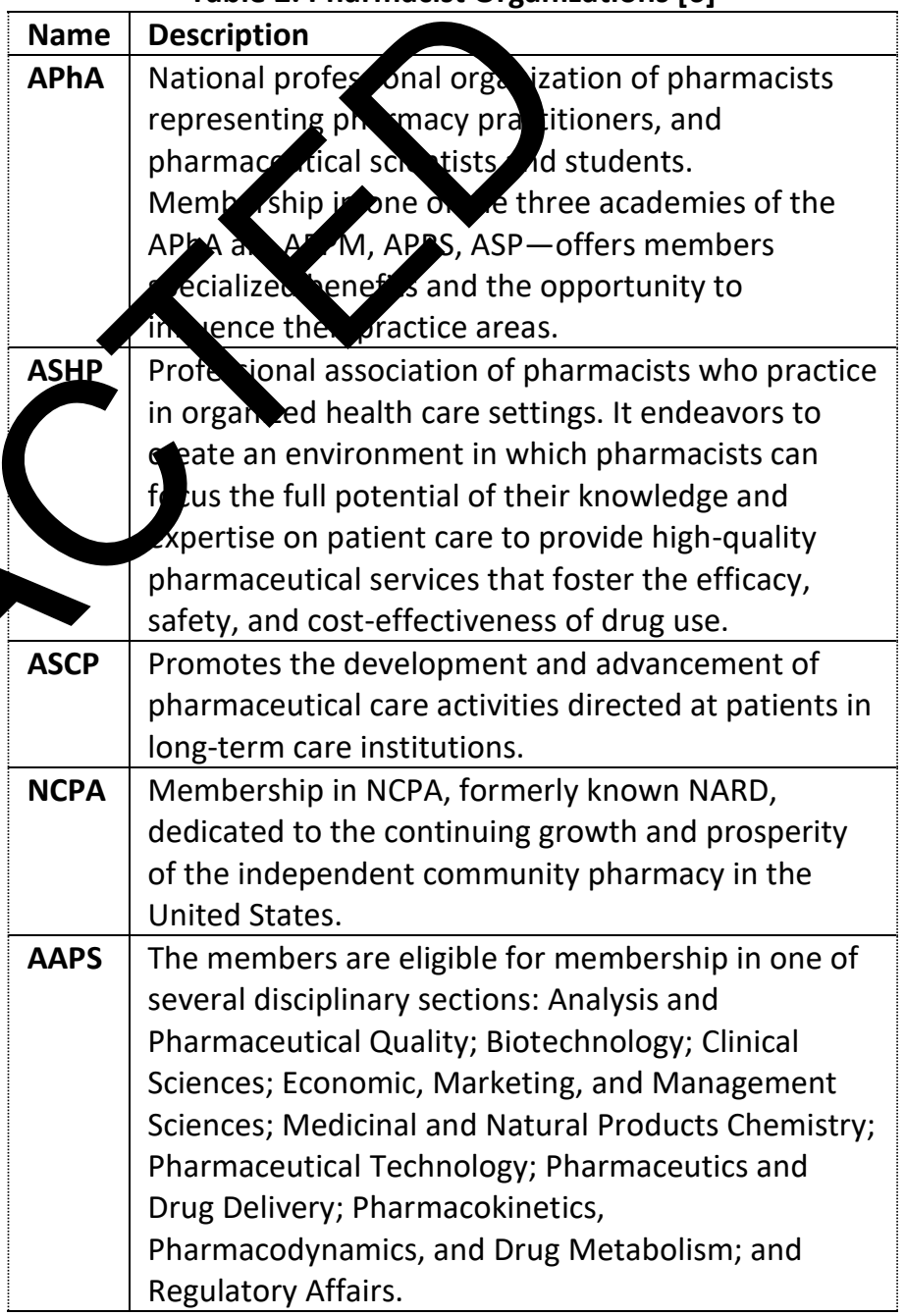

Job market in Developed Countries

The scope of pharmacist practice is expanding across the world. Pharmacist prescribing has taken root in the US, UK and Canada. In Alberta, Canada, three types of pharmacist prescribing were defined 1) adapting a prescription (i.e., adapting an existing prescription or extending a prescription for continuity of care, 2) prescribing in an emergency, and 3) additional prescribing authority (APA) (i.e., prescribing a new medication for initial therapy or to manage ongoing conditions). Albertan pharmacists do not require a written 
agreement with a physician to prescribe as in the US model. Furthermore, pharmacists do not require additional training with a physician partner as in the UK model [64]. National Center for Health Workforce Analysis, sponsored by the Health Resources and Services Administration, projected that between 2012 and 2025 the pharmacist supply, adjusting for new entrants as well as exit from the labor force demand would increase by $16 \%$. The BLS estimates an increase of 17,400 jobs over 10 years, while there are currently over 14,500 new graduates per year. Further, as acknowledged in the HRSA forecasting report, greater integration of pharmacists into medical teams across a variety of potential settings, along with more advanced clinical roles, has the potential to substantially boost demand well beyond current expectations [65]. Government-subsidized health care facilities in Malaysia warrants affordable health care services for the nations, which incurs reasonable treatment charges for both standard and specialist care. This makes high patient volumes and long waiting time a norm in these settings [66]. The integration of a pharmacist into private GP clinics has the potential to contribute to quality use of medicines. Pharmacists in the public health clinics possess complete control over the supply of medicines. Collaborative medicines management services delivered by pharmacists and GPs have already been successful in identifying and resolving medication-related problems, improving patient outcomes, and optimizing drug use and costs. Such services include pharmacist-led medication review. where pharmacists assess medications, monitor disease progression, and provide recommendations to medication management plan. Consumers genera pharmacist integration into private GP clini expressed concerns that need to be add ssed if fective diabetes care is to be provided from con un pharma in Malaysia [68,69]. In recent years, a n mber of untries have extended prescribing rights to $\mathrm{p}$ armacists in ariety of formats. The latter includes ind ende prescribing, which is a developing area of practice for $p$ h acists $j$ secondary care. Potential opportunitied $p$ sento oy wide scale implementation of ph nacist orescribung in secondary care include improved prescri safety, more efficient pharmacist medication reviews, increas scope of practice with greater pharmacist integration into acte patient care pathways and enhanced professional or job satisfaction [70]. NHS England (NHSE) is facing a growing GP workforce crisis, with continuing problems around GP recruitment, retention, and retirement rates. Approximately $30 \%$ of GP partners have reported not being able to fill a GP vacancy in their practice for at least 12 months [71]. In July 2015, as part of the Five Year Forward View 4 and the new deal for general practice, NHSE launched the clinical pharmacists in general practice scheme to address issues of capacity. The scheme initially provided $f 31$ million funding to general practices to employ pharmacists over 3 years. Phase 1 of the scheme saw approximately 460 pharmacists employed at around 650 practices across 88 sites. In April 2016, NHSE confirmed expansion of the scheme, with an additional $£ 112$ million for a further 1500 clinical pharmacist posts by 2020-2021 [72]. All pharmacists employed through the scheme are supported by the Health Education Englandfunded GPPTP, an 18-month mandatory training program delivered by the CPPE at the University of Manchester [73].

\section{Success of Pharmacist-led Interventions}

For hospital pharmacists, the expanded scope of practice includes activities such as changing drug dosages and other aspects of patients' prescriptions, therapeutic substitution, initiation of prescription drug therapy (including therapy for minor ailments), and ordering and interpretation of laboratory tests, all of which have further focused the pharmacist's role within a patient-centered of care. Knowledge about drugs and diseases and $t$ ability apply this knowledge are key components of succ. Phar acists are engaged in an expanding scope practio and ave dramatic impacts on patient and onomi ou nes. Reviewing pharmacy literature raved at pharmacist success is driven by pharmaci engage ent practice activities and innate or cultivat an rsonal ch cteristics.

Wiedication Ac erence Improvement and Therapeutic Cost Minimization

vpically, therence rates of $80 \%$ or more are needed for o mal erapeutic efficacy [79]. Of the 32 million adult Americans who take 3 or more medications daily, $75 \%$ are nomddherent. Nonadherence accounts for up to $70 \%$ of all medication-related hospital visits and the estimated annual cost of prescription drug-related morbidity and mortality resulting from nonoptimized medication therapy was $\$ 528.4$ billion in 2016 US dollars" with a low end of $\$ 495.3$ billion and high end of $\$ 672.7$ billion. The estimated that nonoptimized drug therapy results in about 275,689 deaths per year [74-76]. In a 2- to 5-minute conversation with patients, pharmacists used motivational interviewing techniques to improve patient adherence to drug therapy. Results were as follows:

- Mean adherence rates were improved for all five medication classes studied-calcium channel blockers, oral diabetes medications, beta-blockers, statins, and reninangiotensin system antagonists - in the intervention group compared with the control group.

- Health care costs were lower in the intervention group compared with the control group for patients who were using oral diabetes medications and statins [77].

- Personalized telephone advice from a pharmacist can improve medication adherence in patients with long-term conditions, research shows [78]. Ultimately, pharmacists' efforts to improve adherence can positively impact patient care and generate substantial clinical and financial rewards [79]. Studies have shown that ambulatory care and inpatient pharmacist medication recommendations are well received, with acceptance rates by physicians ranging $70-90 \%[80]$. 


\section{In Pediatric Wards}

Clinical pharmacists provide beneficial services to adult patients, though their benefits for pediatric hospital patients are less defined. Clinical pharmacist services had a positive impact on pediatric patient care. Medication errors intercepted by pharmacists included over- and under-dosing, missed doses, medication history gaps, allergies, and near misses. Interventions to address these errors were positively received, and implemented by physicians, with an average acceptance rate of over $95 \%$. The benefits of pharmacist involvement appear greatest when directly involved in ward rounds, due to being able to more rapidly identify medication errors during the prescribing phase, and provide real-time advice and recommendations to prescribers. However, findings from systemic review reveals the following:

- Complex pediatric conditions can require multiple pharmaceutical treatments, utilized in a safe manner to ensure good patient outcomes

- The benefits of pharmacist interventions when using these treatments are well-documented in adult patients, though less so in pediatric patients

- Pharmacists are adept at identifying and managing medication errors for pediatric patients, including incorrect doses, missed doses, and gaps in medication history. A prospective study by Fortescue et al. showed that wardbased clinical pharmacists prevented $81 \%$ of potentiall harmful medication errors.

- PPAG endorses and advocates for the involvement pediatric pharmacists in pharmacogenomic test so d in using those results to provide safe medication use in pediatric patients of al

- Interventions recommended by pharm ists are nerally well-accepted by prescribing physig ns, specially chen recommendations can be made during th prescribing
phase of treatment

- Increased pharmacist prese in PICU is associated with increased interventions preve con of adverse drug events. Pharma st p ticipo op during rounds and order entry substa ally in roved the care of critically sick children and should couraged.

- Clinical pharmacist-in ted education resulted in improved medication understanding and adherence, improved patient satisfaction, and control of chronic medical conditions [81-87].

\section{Chronic Disease Management}

A research that was done in Katmandu showed that $44 \%$ of the community pharmacy professionals always counseled on the importance of exercise and diet control. These findings are also consistent with a study in Scotland [88]. Since diabetes is a chronic lifelong condition, adherence to medications and selfmonitoring of blood glucose are quite challenging to the patients. ADA recommend that $\mathrm{HbA} 1 \mathrm{c}$ should be measured at regular intervals in all patients with diabetes. Impact of diabetes self-care intervention by pharmacist reported to significantly reduce the $\mathrm{HbA} 1 \mathrm{C}$ levels of diabetic patients along with the reduction of yearly healthcare cost [70]. Another study presented that an adequate duration of pharmacist-led pharmaceutical care was effective in improving $\mathrm{HbAlc}$ in patients with diabetes in both LMIc and Hic [89, 90]. CVD is the major cause of death in patients with diabetes and is about two times more frequent in these patients compared with people without diabetes. Pharmacist care improves the management of outpatients with major modifiable CVD risk factors. Pharmacists can help fill the gap as primary care providers and can contribute to the control of CVD risk factors by their knowledge of medications, their easy accessibility for patients, and their collaborative practice with physicians. Pharmacist care was associated with signt reduction in blood pressure and serum cholesterol an a reduc $n$ in the risk of smoking. It has been evaluated of docum nted that pharmacists providing medicati recon iation specially during transition of care, educatis paties on medications, and providing collaborativerme ica on mangement lead to positive changes in the pati st outco in ading but not limited to decreasing in hog ra ations a re-admissions [91-93]. Through a combination educational and organizational support, a meral practiobased pharmacist led collaborative nterventip can improve statin prescribing and achievement of holestero argets in a high-risk primary care-based population

(1)

Mrucation History Taking, Error prevention and Reconciliation As it was discussed earlier that about $30 \%-40 \%$ of patients receive treatment that is not based on scientific evidence, and $20 \%-25 \%$ receive treatments that are either not needed or potentially harmful. In addition, it is estimated that more than $50 \%$ of Americans do not take medications as they are prescribed, and approximately one third do not finish the course of therapy or skip doses [95]. In the USA, it has been reported that $3.7 \%$ of all hospitalized patients experienced an adverse event, and medication errors alone resulted in 7000 deaths annually. The average health expenditure per person in sub-Saharan Africa countries is below US\$100 per annum compared with US\$6110 in Australia and US\$9146 in USA, while 1.5-6.5\% of hospital admissions are attributed to ADEs and 2.5$47 \%$ of inpatients encountered an ADE during their hospital stay. One-fifth to more than a half of the reported ADEs were severe events, of which ADE related fatalities were reported in $0.07-2.9 \%$ of patient admissions to hospital [96]. More than $25 \%$ of medication errors can be attributed to incorrect medication histories, demonstrating that this is an error-prone process. More than 33\% of patients had at least one medication discrepancy at admission, and $85 \%$ of these originated from the medication history. Greater than $97 \%$ of medication histories documented by health care providers other than pharmacists were associated with at least one medication discrepancy. Medication discrepancies, within the medication reconciliation process, occur in approximately $70 \%$ of admitted and discharged patients, $29.5 \%$ of which can lead to harm and ADEs 
[99]. Pharmacy technicians have been shown to reduce medication list discrepancies as part of various medication reconciliation programs [97]. Obtaining an accurate medication history during transitions of care has been shown to reduce errors that could lead to patient harm and is the foundation of the medication reconciliation process. Use of a pharmacy technician may provide the benefits of pharmacist-based medication history collection while being financially advantageous. Cooper and colleagues discussed the advantages of a standardized pharmacy technician medication history program that helped improve provider compliance with discharge medication reconciliation [98]. Overall, pharmacy technicians were more effective in executing the logistical details of the service, seeing more patients, and clarifying the drug and route as well as removing discontinued and duplicate medications from the list more often [97]. Involvement of pharmacy personnel during the medication reconciliation process can be an essential component in reducing medical errors. With the addition of the pharmacy department during the admission process, accuracy, cost savings, and patient safety across all phases and transition points of care were achieved [100].

\section{Conclusion}

As the health care system changes, the line between the roles of pharmacist and physician can become blurred. What differentiates a pharmacy role from a medical role? A simpl answer is that what the state licensing laws allow each profession to perform provides that differentiation over my 50 years in practice, legislative changes in ractice acts have tended to blur the differentiation. When yu $c 0$ memu a treatment for the problem, you are acting an ind endent practitioner. As the FDA and some state no toward slass of drugs that pharmacists can prescri'e/recom, nd, the line between physician and pharmacis slurs yet again--Fred $\mathrm{M}$. Eckel, Editor-in-Chief, Pharma Tim From the above consideration, it is clear that the armacis have definite beneficial roles regarding realy mats Pharmacist is the legally qualified and pression acomperent person to handle drugs and allied supplies ared tor the patients within and outside the hospital. It a matter of regret that the government of our country is toning very little effort to employ highly skilled pharmacy personnel in different sectors of the health services. But in the developed countries, Pharmacists are in unique position in this regard. So, the governmental health policy should be modified by incorporation Pharmacist in different s. The huge divides that exist in patient education and income levels can be alleviated by design and use of costeffective educational materials and the visual media. The development and empowerment of the pharmacist can occur only if appropriate steps are taken to ensure that pharmacy licenses are awarded only to qualified pharmacy graduates and adequate educational training is imparted so that pharmacists remain and are rewarded for being the best sources of information related to medication use. Successful policies in this regard and implementation of appropriate regulation will ensure the development of a safer and more effective pharmaceutical public health system, which can in turn, directly translate to improved health of all citizen sectors to improve and ensure the health service for the well-being of people of our country.

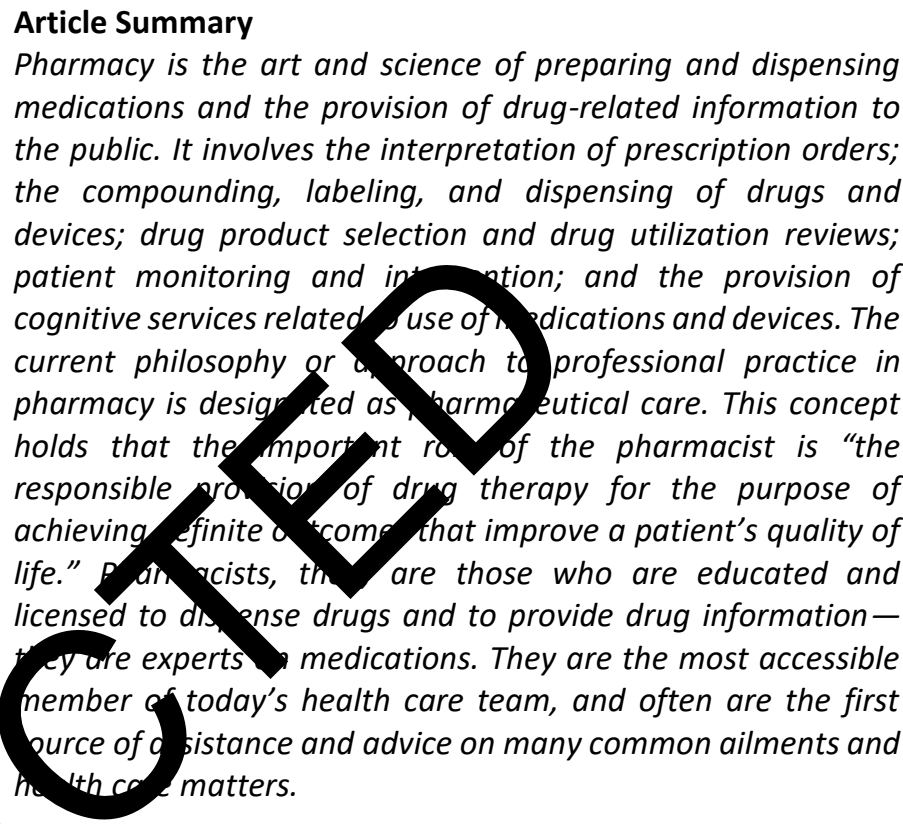

Aloniteviations: American Association of Colleges of Pharmacy (AACP); American Association of Pharmaceutical Scientists (AAPS); American College of Clinical Pharmacy (ACCP), Accreditation Council for Pharmacy Education (ACPE); American Pharmacists Association (APhA); Academy of Pharmacy Practice and Management (APPM); Academy of Pharmaceutical Research and Science (APRS); Academy of Students of Pharmacy (ASP); American Society of HealthSystem Pharmacists (ASHP); American Society of Consultant Pharmacists (ASCP); Direct and Indirect Remuneration (DIR) Health Related Quality of Life (HRQL); National Community Pharmacists Association (NCPA); National Association of Retail Druggists (NARD); Royal Pharmaceutical Society (RPS); Medication-Related Problems (MRPs); Clinical Pharmacist Practitioner (CPP); Health Maintenance Organizations (HMOs); Interprofessional collaboration (IPC); Emergency Operations Plan (EOP); Joint Commission of Pharmacy Practitioners (JCPP); Pharmacists' Patient Care Process (PPCP); Accreditation Council for Pharmacy Education (ACPE); Bureau of Labor Statistics (BLS); Health Resources \& Services Administration (HRSA); National Health Service England (NHSE); Centre for Pharmacy Postgraduate Education (CPPE); General Practice Pharmacist Training Pathway (GPPTP); Pediatric Intensive Care Unit (PICU); Pediatric Pharmacy Advocacy Group (PPAG); Low- And MiddleIncome Countries (LMIC); High-Income Countries (HIC); American Diabetes Association (ADA); Glycated Haemoglobin (A1c) (HbA1c); Bangladesh National Scientific and Technical Documentation Centre (BANSDOC); University of Illinois at 
Chicago (UIC); Medication Therapy Management (MTM); Collaborative Pharmacy Practice (CPP); Continuing Professional Development (CPD); Vaccine-Preventable Diseases (VPDs); Advisory Committee on Immunization Practices (ACIP); National Community Pharmacists Association (NCPA); Antiretroviral Therapy (ART)

Acknowledgement: It is a great honor and gratitude to be pharmacists in research and education process. All pharmacists, officials, journalists, magazine analysts and associates that I met in this purpose, were very kind and helpful. I'm thankful to Dr. Surrey M. Walton, Department of Pharmacy Systems Outcomes and Policy, UIC College of Pharmacy for his precious time to review my article and given his thoughtful suggestions. I'm also grateful to seminal library of Faculty of Pharmacy, University of Dhaka and BANSDOC Library, Bangladesh for providing me books, journal and newsletters. The greatest help was from students and colleagues who continually supported me in collection and data extraction from books, journals, newsletters and precious time in discussion followed by providing information on patient compliance, rational drug use and therapeutic monitoring. A portion of this article is long been lectured as course material. So, it is very much helpful for me to deliver better than before as many more things are studied.

Ethics approval and consent to participate: Animal and Human experiment: N/A Human Data Submission Approval: N/A

Consent for publication: Consent to pubthidual Person's data: N/A Availability of data and materials: ata sharing: Plase contact author for data request Competing interests: The auther a des tha no competing interests Funding: Funding from dividy Larganlzation: N/A Authors' contributions: dividurarcontributions of authors: N/A

\section{Reference}

1. APhA. Principles of Practice for Pharmaceutical Care. Available From: https://www.pharmacist.com/principles-practicepharmaceutical-care.

2. Jaiprakash V. Kokan, Pawan S. Avhad Role of Pharmacist in Health Care System The Journal of Community Health Management, January-March 2016;3(1):37-40.

3. Stephanie Y. Crawford Pharmacists' Roles in Health Promotion and Disease Prevention American Journal of Pharmaceutical Education 2005; 69 (4) Article 73.

4. Ferreri SP, Cross $D^{D}$ Aanes $D$, Jenkins $T$, Meyer D, Pittenger A. Aca mic Pharn cy: Where is Our Influence?. A J Ph rm Edud 2017;81(4):63.

5. Page E. $H$ pharmac start a career in the pharma utic mdustry. The Pharmaceutical Journal 9

6. $\mathrm{MP} 201$

JL. Chap scope of Pharmacy. In: Remington: The S. nce and Practice Of Pharmacy. Author: Joseph P Reming n; Paul Beringer Publisher: Philadelphia: Lip incott Williams \& Wilkins, 2006.

7. Atl ison J, De Paepe K, Pozo AS, et al. A Study on How ustrial Pharmacists Rank Competences for Pharmacy Practice: A Case for Industrial Pharmacy Specialization. Pharmacy (Basel). 2016;4(1):13. Published 2016 Feb 6. doi:10.3390/pharmacy4010013

8. Chisholm-Burns MA, Gatwood J, Spivey CA. Economic Analysis of Obtaining a PharmD Degree and Career as a Pharmacist. Am J Pharm Educ. 2015;79(8):117.

9. Brazeau GA, Meyer SM, Belsey M, et al. Preparing pharmacy graduates for traditional and emerging career opportunities. Am J Pharm Educ. 2009;73(8):157.

10. Rossheim J. Diverse Opportunities Await Pharmacists in Industry. Available From: https://www.monster.com/careeradvice/article/pharma-industry-jobs-for-pharmacists.

11. Wiedenmayer K, Summers RS, Mackie CA and others. Developing pharmacy practice $A$ focus on patient care HANDBOOK - 2006 EDITION. Available From: http://apps.who.int/iris/bitstream/handle/10665/6939 9/?sequence $=1$.

12. The Health Promotion Strategic Framework. Available From: https://www.healthpromotion.ie/hpfiles/docs/HPSF_HSE.pdf.

13. Tseng A, Foisy $M$, Hughes $C A$, et al. Role of the Pharmacist in Caring for Patients with HIV/AIDS: Clinical Practice Guidelines. Can J Hosp Pharm. 2012;65(2):125-45.

14. NICE. Contraceptive services for under 25s. Public health guideline Published: 26 March 2014. 
15. Tong S, Amand C, Kieffer A, Kyaw MH. Trends in healthcare utilization and costs associated with pneumonia in the United States during 2008-2014. BMC Health Serv Res. 2018;18(1):715. Published 2018 Sep 14. doi:10.1186/s12913-018-3529-4.

16. Katoue MG. Role of pharmacists in providing parenteral nutrition support: current insights and future directions. Integr Pharm Res Pract. 2018;7:125140. Published 2018 Oct 2. doi:10.2147/IPRP.S117118.

17. Gelayee DA, Mekonnen GB. Pharmacy students' provision of health promotion counseling services during a community pharmacy clerkship: a cross sectional study, Northwest Ethiopia. BMC Med Educ. 2018;18(1):95. Published 2018 May 4. doi:10.1186/s12909-018-1216-0.

18. Saxena P, Mishra A, Nigam A. Evaluation of Pharmacists' Services for Dispensing Emergency Contraceptive Pills in Delhi, India: A Mystery Shopper Study. Indian J Community Med. 2016;41(3):198-202.

19. Chin-Quee DS, Stanback J, Orr T. Family planning provision in pharmacies and drug shops: an urgent prescription. Contraception. 2018 Nov;98(5):379-382. doi: 10.1016/j.contraception.2018.08.013. Epub 2018 Aug 28. PubMed PMID: 30170029.

20. Santschi V, Chiolero A, Paradis G, Colosimo AL, Burnand $B$. Pharmacist interventions to improve cardiovascular disease risk factors in diabetes: a systematic review and meta-analysis of randomized controlled trials. Diabetes Care. 2012;35(12)

21. FIP. Pharmacists supporting Women and use of medicines. Empowering inform 2018. Available From: https://www.fip.org/files/fip/pup at. ss/Pharm_ists -supporting-women-responsib-use-mes ines.pdf

22. Toklu HZ, Hussain A. The cb iging face of P rrmacy practice and the need for new codel of pharmacy education. J Young Pharm. $20 ; 5(2) ;>40$.

23. Ali A, Katz DL. Dise seP vent, a Health Promotion: Hor ntegr , Me Medicine Fits. Am J Prev Med. 2015;49(5 S 3$):$ S230 40

24. Institute for Work \& valth (Toronto). What researchers mean by Pl mary, secondary and tertiary prevention. Published: April 2015.

25. National Academies of Sciences, Engineering, and Medicine; Health and Medicine Division; Board on Population Health and Public Health Practice; Committee on Community-Based Solutions to Promote Health Equity in the United States; Baciu A, Negussie Y, Geller A, et al., editors. Communities in Action: Pathways to Health Equity. Washington (DC): National Academies Press (US); 2017 Jan 11. 8, Community Tools to Promote Health Equity.
26. Pharmacy Board of Australia. Guidelines for dispensing of medicines. Available From:

http://apps.who.int/medicinedocs/en/m/abstract/Js17 807en/.

27. Management Sciences for health (2012). chapter 30. Ensuring good dispensing practices. Available From: http://apps.who.int/medicinedocs/documents/s19607 en/s19607en.pdf

28. Management Sciences for health (2012). chapter 45. Hospital pharmacy management. Available From: http://apps.who.int/medicinedocs/documents/s19622 en/s19622en.pdf.

29. Warner DJ (ASHP). The Clinical Pharmacists' Role in Patient Safety. Avail rom: https://www.hay d.qa/En, IIEvents/CPC/Prog $n$ /Docum nts/David-WarnerPlenary1.p

30. FIP. Rev d Fip sel Suments On The Future Of Hospital har acy. Anproved September 2014, Ba skok, Th land s revisions of the initial 2008 Gound y-Smith S. The Connected Community Pharmac) Benefits for Healthcare and Implications for He-lth Policy. Front Pharmacol. 2018;9:1352.

Pu jshed 2018 Nov 28. doi:10.3389/fphar.2018.01352 wartzberg E, Nathan JP, Avron S, Marom E. Clinical and other specialty services offered by pharmacists in the community: the international arena and Israel. Isr J Health Policy Res. 2018;7(1):59. Published 2018 Dec 1. doi:10.1186/s13584-018-0251-y.

33. Scott DM. United States Health Care System: A Pharmacy Perspective. Can J Hosp Pharm. 2016;69(4):306-15.

34. Hermansyah A, Sainsbury E, Krass I. Multiple policy approaches in improving community pharmacy practice: the case in Indonesia. BMC Health Serv Res. 2018;18(1):449. Published 2018 Jun 14. doi:10.1186/s12913-018-3258-8.

35. Barber N, Smith F, Anderson S. Improving quality of health care: the role of pharmacists. Improving quality of health care: the role of pharmacists Quality in Health Care 1994;3:153-158.

36. Mahmoodpoor A, Kalami A, Shadvar K, Entezari-Maleki $\mathrm{T}$, Hamishehkar H. Evaluation of Clinical Pharmacy Services in the Intensive Care Unit of a Tertiary University Hospital in the Northwest of Iran. J Res Pharm Pract. 2018;7(1):30-35.

37. Dalton K, Byrne S. Role of the pharmacist in reducing healthcare costs: current insights. Integr Pharm Res Pract. 2017;6:37-46. Published 2017 Jan 25. doi:10.2147/IPRP.S108047.

38. Lampkin SJ, Gildon B, Benavides S, Walls K, Briars L. Considerations for Providing Ambulatory Pharmacy Services for Pediatric Patients. J Pediatr Pharmacol Ther. 2018;23(1):4-17. 
39. de Barra $M$, Scott $C L$, Scott NW, Johnston $M$, de Bruin $\mathrm{M}$, Nkansah N, Bond CM, Matheson Cl, Rackow P, Williams AJ, Watson MC. Pharmacist services for nonhospitalised patients. Cochrane Database Syst Rev. 2018 Sep 4;9:CD013102. doi: 10.1002/14651858.CD013102. Review. PubMed PMID: 30178872.

40. Hawes EM, Misita C, Burkhart JI, McKnight L, Deyo ZM, Lee RA, Howard C, Eckel SF. Prescribing pharmacists in the ambulatory care setting: Experience at the University of North Carolina Medical Center. Am J Health Syst Pharm. 2016 Sep 15;73(18):1425-33. doi: 10.2146/ajhp150771. PubMed PMID: 27605321.

41. de Sousa IC, de Lima David JP, Noblat Lde A. A drug information center module to train pharmacy students in evidence-based practice. Am J Pharm Educ. 2013;77(4):80.

42. Alamri SA, Ali Al Jaizani R, Naqvi AA, Ghamdi MSA. Assessment of Drug Information Service in Public and Private Sector Tertiary Care Hospitals in the Eastern Province of Saudi Arabia. Pharmacy (Basel). 2017;5(3):37. Published 2017 Jul 4. doi:10.3390/pharmacy5030037.

43. WHO web. The Role of the Pharmacist in the HealthCare System - Preparing the Future Pharmacist: Curricular Development, Report of a Third WHO Consultative Group on the Role of the Pharmacist Vancouver, Canada, 27-29 August 1997.

44. Malone PM, Fagan NL, Malesker MA; Nelson Chapter 12. Pharmacy and Therapeutics In: Drug Information: A Guide for Pha Edition (Drug Information (McGraw 11)) 4th l. Patrick M. Malone, Karen L. Kier, John E an ich, Publ _ed by McGraw-Hill Medical; 4 edi`on (Augu_. 17, 2011).

45. Scott DM, Strand M, Undep A, Anderson G, Varens A, Liu X. Assessment of pha acist delivery of public health services in ruraland an are in lowa and North Dakota. Pha MPl t (G) ar , 2016;14(4):836.

46. Bradley F, Seste E, Ma all C, Curts C. Evolution of the general pract narmacist's role in England: a longitudinal study. BN Gen Pract. 2018;68(675):e727e734.

47. Green $B N$, Johnson CD. Interprofessional collaboration in research, education, and clinical practice: working together for a better future. J Chiropr Educ. 2015;29(1):1-10.

48. Bridges DR, Davidson RA, Odegard PS, Maki IV, Tomkowiak J. Interprofessional collaboration: three best practice models of interprofessional education. Med Educ Online. 2011;16:10.3402/meo.v16i0.6035. Published 2011 Apr 8. doi:10.3402/meo.v16i0.6035.
49. Stringer K, Curran V, Asghari S. Pharmacists and family physicians: improving interprofessional collaboration through joint understanding of our competencies. Front Pharmacol. 2013;4:151. Published 2013 Dec 5. doi:10.3389/fphar.2013.00151

50. Bell C, Daniel S. Pharmacy Leader's Role in Hospital Emergency Preparedness Planning. Hosp Pharm. 2014;49(4):398-404.

51. Boechler L, Despins R, Holmes J, et al. Advocacy in pharmacy: Changing "what is" into "what should be". Can Pharm J (Ott). 2015;148(3):138-41.

52. Cooley J, Lee J. Implementing the Pharmacists' Patient Care Process at a Public Pharmacy School. Am J Pharm Educ. 2018;82(2):63

53. Galal SM, Carr-L $c$ SM, G nez S, et al. A collaborative app ach to co bining service, teaching, and researf. Am J Mrm E ac. 2014;78(3):58.

54. Reidt S, Grgan Larso Blade MA. The role of a pharmad 0 he home care team: a collaborative $m$ el betw a a rege of pharmacy and a visiting A agency. ne Healthc Nurse. 2013 Feb;31(2):807; quit 8-9. doi: 10.1097/NHH.0b013e3182778f5f. PubMed MID: 23314201.

55. Brewn MT, Bussell JK. Medication adherence: WHO car 5?. Mayo Clin Proc. 2011;86(4):304-14.

6. Tr Pfizer Guide To Careers In Pharmacy. Published by ECOF: HIGH DENSITY MOBILE FILING SYSTEM, 2017-1017 03:58:51 Available From: http://fliphtml5.com/Inym/tjzn/basic/101-150.

57. John $\mathrm{C}$. The changing role of the pharmacist in the $21 \mathrm{st}$ century. The Pharmaceutical Journal8 JAN 2018.

58. Barrett J. Pharmacists Play Key Role in the Future of Health Care. Pharmacy Times JUNE 07, 2017.

59. Pharmacy Schools Council. The future role of the pharmacist. News 26.03.18.

60. Byne T. What Could the Role of the Pharmacist be in the Future? British Pharmaceutical Students' Association (BPSA) News.

61. Baker KR. Two Crucial Skills Pharmacists Will Need to Succeed in the Future. DrugTopics Mar 5, 2018

62. Warner B. Wanted: young pharmacists to shape the future. NHS England Blog 29 January 2018.

63. Pharmacy's Global Transformation Is Pharma's Opportunity. McCANN Health March 2017.

64. Guirguis LM, Hughes CA, Makowsky MJ, et al. Development and validation of a survey instrument to measure factors that influence pharmacist adoption of prescribing in Alberta, Canada. Pharm Pract (Granada). 2018;16(1):1068.

65. Walton SM, Manasse HR. Is It a Good Time to Be a Pharmacist in the US?. Pharmacy (Basel). 2018;6(3):61. Published 2018 Jul 3. doi:10.3390/pharmacy6030061. 
66. Lau BT, Nurul-Nadiah-Auni AR, Ng SY, Shuen-Wong N. Satisfaction of patients receiving value added-services compared to traditional counter service for prescription refills in Malaysia. Pharm Pract (Granada). 2018;16(1):1075.

67. Saw PS, Nissen LM, Freeman C, Wong PS, Mak V. Health care consumers' perspectives on pharmacist integration into private general practitioner clinics in Malaysia: a qualitative study. Patient Prefer Adherence. 2015;9:467-77. Published 2015 Mar 19. doi:10.2147/PPA.S73953.

68. Lee EL, Wong PS, Tan MY, Sheridan J. What role could community pharmacists in Malaysia play in diabetes self-management education and support? The views of individuals with type 2 diabetes. Int J Pharm Pract. 2018 Apr;26(2):138-147. doi: 10.1111/ijpp.12374. Epub 2017 Jun 2. PubMed PMID: 28574154.

69. Bourne RS, Baqir W, Onatade R. Pharmacist independent prescribing in secondary care: opportunities and challenges. Int J Clin Pharm. 2016 Feb;38(1):1-6. doi: 10.1007/s11096-015-0226-9. PubMed PMID: 26613738.

70. Jamshed SQ, Siddiqui MJ, Rana B, Bhagavathula AS. Evaluation of the Involvement of Pharmacists in Diabetes Self-Care: A Review From the Economic Perspective. Front Public Health. 2018;6:244. Published 2018 Sep 3. doi:10.3389/fpubh.2018.00244

71. ICM Unlimited British Medical Association survey of GPs in England: full report. 2016 https://www.bma.org.uk//media/files/pdfs/collective\%20voice/ Onegotiations/training\%20and\%20 survey-of-gps-in-england-final-rert. If?la=en (accessed 20 Aug 2018).

72. NHS England General pract forward view. 016 https://www.england.nk $\mathrm{k} / \mathrm{w}$ content/uploads/2016/04/s .pdf (a cessed 20 Aug 2018).

73. Centre for Phar acy Po craduate Education General practice pharmac aining pathway: supporting GP pharmacists of the to ve. 2016 https://www.cppe.ac.u, /wizard/files/generalpractice/gpptp-promo-brochure.pdf (accessed 20 Aug 2018).

74. Aungst T. Does Nonadherence Really Cost the Health Care System $\$ 300$ Billion Annually? Pharmacy Times ${ }^{\circledR}$ June 01, 2018.

75. Haskins D. Community Pharmacist Services: The Missing Link to Optimizing Medication Adherence. Pharmacy Times ${ }^{\circledR}$ September 22, 2017.

76. Oswald K. Non-adherence: medicine's weakest link. The Pharmaceutical Journal 8 February 2018

77. McDonough RP. Identifying and resolving medication nonadherence. Health Aff. 2014; 33: 1444-1452.
78. Adams B. Pharmacist-led telephone advice 'improves medication adherence. The Pharmaceutical Journal 17 February, 2016.

79. Downs J, Tillman F. Medication Adherence: The Elephant in the Room. US Pharm. 2018;43(1)30-34.

80. Combs K. Let's Talk: Medication Adherence. Pharmacy Times ${ }^{\circledR}$ July 26, 2017.

81. Drovandi A, Robertson K, Tucker M, Robinson N, Perks $\mathrm{S}$, Kairuz T. A systematic review of clinical pharmacist interventions in paediatric hospital patients. Eur J Pediatr. 2018 Jun 19. doi: 10.1007/s00431-018-3187-x. [Epub ahead of print] Review. PubMed PMID: 29915870.

82. Tripathi S, Crabtree ryer KR, Graner KK, Arteaga GM. Impact of Cli cal Phan acist on the Pediatric Intensive Care Pr tice: An 1 Year Tertiary Center Experience Pediat harm Col Ther. 2015;20(4):2908.

83. Kennsdy $\mathrm{U}$, $\mathrm{H}$, Renavides S, Potts A, Sorensen S. Th cole of ped cric pharmacist in personalized ie cine and cal pharmacogenomics for children: pedia pharmacogenomics working group. J Pediatr Pharmaco Ther. 2011;16(2):118-22.

84. Ak ggoua DP, Békégnran $C P$, Gro BM, Doffou $E$, Fol uet MA. Assessment of a Clinical Pharmacy Activity Pediatric Inpatient Department in Cote D'ivoire. J Basic Clin Pharm. 2016;8(1):15-19.

Wachman EM, Werler MM. Pharmacologic Treatment for Neonatal Abstinence Syndrome: Which Medication Is Best? JAMA Pediatr. Published online January 22, 2019. doi:10.1001/jamapediatrics.2018.5029

86. Perrin JH. Pediatrician and Compounding Pharmacist: A Dangerous Liaison. Arch Pediatr Adolesc Med. 1996;150(2):224-226. doi:10.1001/archpedi.1996.02170270106020

87. Lea S. Eiland, Kim Benner, Karl F. Gumpper, Melissa K. Heigham, Rachel Meyers, Katherine Pham, Amy L. Potts; ASHP-PPAG Guidelines for Providing Pediatric Pharmacy Services in Hospitals and Health Systems, American Journal of Health-System Pharmacy, Volume 75, Issue 15, 1 August 2018, Pages 1151-1165, https://doi.org/10.2146/ajhp170827

88. Teka NT, Baye AM. Counseling practice of community pharmacists for diabetes mellitus patients in Addis Ababa, Ethiopia. BMC Res Notes. 2018;11(1):700. Published 2018 Oct 4. doi:10.1186/s13104-018-3807-6.

89. Jeong $\mathrm{S}$, Lee $\mathrm{M}$, Ji E. Effect of pharmaceutical care interventions on glycemic control in patients with diabetes: a systematic review and meta-analysis. Ther Clin Risk Manag. 2018;14:1813-1829. Published 2018 Sep 28. doi:10.2147/TCRM.S169748. 
90. Bukhsh A, Nawaz MS, Ahmed HS, Khan TM. A randomized controlled study to evaluate the effect of pharmacist-led educational intervention on glycemic control, self-care activities and disease knowledge among type 2 diabetes patients: A consort compliant study protocol. Medicine (Baltimore). 2018;97(12):e9847.

91. Santschi V, Chiolero A, Paradis G, Colosimo AL, Burnand $B$. Pharmacist interventions to improve cardiovascular disease risk factors in diabetes: a systematic review and meta-analysis of randomized controlled trials. Diabetes Care. 2012;35(12):2706-17.

92. Santschi V, Chiolero A, Burnand B, et al. Impact of pharmacist care in the management of cardiovascular disease risk factors: a systematic review and metaanalysis of randomized trials. Arch Intern Med 2011;171:1441-53. 10.1001/archinternmed.2011.399.

93. Lowrie R, Lloyd SM, McConnachie A, Morrison J. A cluster randomised controlled trial of a pharmacist-led collaborative intervention to improve statin prescribing and attainment of cholesterol targets in primary care. PLoS One. 2014;9(11):e113370. Published 2014 Nov 18. doi:10.1371/journal.pone.0113370

94. Cheng JW. Current perspectives on the role of the pharmacist in heart failure management. Integr Pharn Res Pract. 2018;7:1-11. Published 2018 Mar 9. doi:10.2147/IPRP.S137882.
95. Fischer F, Lange K, Klose K, Greiner W, Kraemer A. Barriers and Strategies in Guideline Implementation-A Scoping Review. Healthcare (Basel). 2016;4(3):36. Published 2016 Jun 29. doi:10.3390/healthcare4030036

96. Digiantonio N, Lund J, Bastow S. Impact of a PharmacyLed Medication Reconciliation Program. P T. 2018;43(2):105-110.

97. Petrov K, Varadarajan R, Healy M, Darvish E, Cowden C. Improving Medication History at Admission Utilizing Pharmacy Students and Technicians: A PharmacyDriven Improvement Initiative. P T. 2018;43(11):676684.

98. Mekonnen AB, McL? AJ, Brien JE, Mekonnen D, Abay Z. Medicati reconc, tion as a medication safety initiative $\mathrm{h}$ thiopia: a tudy protocol. BMJ Open. 2016 (11):ed 2322 ablished 2016 Nov 24. doi:10.1/6/bmi pen-s o-012322

99. Procapio arey $B$, Wynd MA, Finefrock D, $\mathrm{Kc}$ ayashi Feldr an J. Pharmacy collected 1e ration his es in an observation unit. SAGE Open od. 2015;3:2050312115598872. Published 2015 Aug 2. doi:10.1177/2050312115598872

100.Sm th L, Mosley J, Lott S, et al. Impact of pharmacy-led $\mathrm{me}$ ication reconciliation on medication errors during nsition in the hospital setting. Pharm Pract (Granada). 2015;13(4):634.

1.Gupta V, Williams E. Establishing a New Ambulatory Care Practice Site as a Pharmacy Practice Faculty. Pharmacy (Basel). 2018;6(4):111. Published 2018 Oct 11. doi:10.3390/pharmacy6040111. 